\title{
First evidence of convergent lifestyle signal in reptile skull roof microanatomy
}

\author{
Roy Ebel ${ }^{1,2^{*}} \mathbb{D}$, Johannes Müller ${ }^{1,2} \mathbb{B}$, Till Ramm ${ }^{1,2,3,4} \mathbb{B}$, Christy Hipsley ${ }^{3,4}$ and Eli Amson ${ }^{1}$ (D)
}

\begin{abstract}
Background: The study of convergently acquired adaptations allows fundamental insight into life's evolutionary history. Within lepidosaur reptiles-i.e. lizards, tuatara, and snakes-a fully fossorial ('burrowing') lifestyle has independently evolved in most major clades. However, despite their consistent use of the skull as a digging tool, cranial modifications common to all these lineages are yet to be found. In particular, bone microanatomy, although highly diagnostic for lifestyle, remains unexplored in the lepidosaur cranium. This constitutes a key gap in our understanding of their complexly interwoven ecology, morphology, and evolution. In order to bridge this gap, we reconstructed the acquisition of a fossorial lifestyle in 2813 lepidosaurs and assessed the skull roof compactness from microCT cross-sections in a representative subset $(n=99)$. We tested this and five macroscopic morphological traits for their convergent evolution.

Results: We found that fossoriality evolved independently in 54 lepidosaur lineages. Furthermore, a highly compact skull roof, small skull diameter, elongate cranium, and low length ratio of frontal and parietal were repeatedly acquired in concert with a fossorial lifestyle.

Conclusions: We report a novel case of convergence that concerns lepidosaur diversity as a whole. Our findings further indicate an early evolution of fossorial modifications in the amphisbaenian 'worm-lizards' and support a fossorial origin for snakes. Nonetheless, our results suggest distinct evolutionary pathways between fossorial lizards and snakes through different contingencies. We thus provide novel insights into the evolutionary mechanisms and constraints underlying amniote diversity and a powerful tool for the reconstruction of extinct reptile ecology.
\end{abstract}

Keywords: Convergent evolution, Bone, Microanatomy, Skull roof, Fossorial, Lepidosaur

\section{Background}

As a central aspect to the study of life's evolutionary history, convergent acquisitions provide fundamental insights into the constraints that shape the phenotype $[1,2]$. Highly diagnostic examples of such repeated adaptations can be found in tetrapod bone microanatomy. Lifestyles can thus be inferred from the analysis of trabecular networks $[3,4]$ and cross-sections of long bone diaphyses $[5,6]$, ribs $[7,8]$,

\footnotetext{
* Correspondence: royebel@hotmail.de

'Museum für Naturkunde, Leibniz Institute for Evolution and Biodiversity Science, Berlin, Germany

Institute for Biology, Faculty of Life Sciences, Humboldt-Universität zu Berlin, Berlin, Germany

Full list of author information is available at the end of the article
}

and vertebrae $[9,10]$. The secondary acquisition of an aquatic lifestyle in tetrapods, for instance, correlates with a non-pathological increase in bone compactness (i.e. osteosclerosis) and morphological robustness (i.e. pachyostosis) [11-13]. Similarly, a fossorial (i.e. burrowing) lifestyle is typically reflected in limb bone cortical thickness $[14,15]$ but has also been attributed to trabecular anisotropy in mammalian limb bone epiphyses [16, 17]. However, fully fossorial reptiles rarely use their limbs for burrowing and tend to evolve elongate, limb-reduced, head-first burrowing ecomorphs [18-21]. Since this renders the applicability of the established methods impossible, a microanatomical correlate for a fossorial lifestyle in lepidosaurs is yet to be found $[8,22]$. 
Lepidosauria-i.e. lizards, tuatara, and snakes-are the taxonomically and ecologically most diverse non-avian reptile clade [23]. Among other lifestyles, their nearly 11,000 extant species [24] have repeatedly evolved varying degrees of fossoriality [25-27]. A semi-fossorial lifestyle can be found in (1) lacertiform (limbed, lizard-like) taxa occasionally burrowing with their limbs for shelter [28], foraging [29], and reproduction [30] and (2) cryptic serpentiform (limb-reduced, snake-like) taxa that move through substrate of moderate to little resistance, such as leaf litter or loose sand [27]. Contrasting this, fully fossorial lepidosaurs, such as amphisbaenians ("worm lizards") or blind snakes, spend prolonged periods of time underground [31] and are capable of penetrating substrates of higher resistance [32-34]. The evolution of these limbless, fully fossorial ecomorphs in nearly all major lepidosaur clades is a textbook example of convergence [35-37]. It thus appears particularly desirable to identify a microanatomical lifestyle correlate.

We focused our investigation on the lepidosaur cranium, which is exposed to pronounced strain during head-first burrowing [25]. Although it may potentially provide valuable insight into the constraints that repeatedly shaped fossorial ecomorphs, skull roof compactness has never been systematically quantified in lepidosaurs of different ecologies. This poses a key gap in our understanding of their complexly interwoven ecology, morphology, and evolution. In order to bridge this gap, we reconstructed the acquisition of a fully fossorial lifestyle in 2813 lepidosaurs and assessed the skull roof compactness from microCT cross-sections in a representative subset $(n=99)$. Our dataset also comprises the enigmatic stem-amphisbaenian +Cryptolacerta hassiaca (Messel, Eocene of Germany) and four exceptionally wellpreserved fossil rhineurids as early representatives of crown amphisbaenians. Alongside skull roof compactness, we tested five macroscopic morphological traits for a lifestyle signal and convergence. In accordance with previous, mostly qualitative mention in a limited number of taxa $[18,25,32$, 38-40], we expect that a fully fossorial lifestyle will be associated with the convergent acquisition of a thick and osteosclerotic (i.e. compact) skull roof with strongly overlapping bones, elongated cranial and parietal proportions, and a small skull diameter. Alternatively, the absence of both a lifestyle signal and a convergent evolution of these traits would suggest that fossoriality had no universal effect on the skull roof of lepidosaurs as a whole. With our study, we set out to contribute to the controversial discussion regarding the ecological origin of ancient amniote lineages, in particular Serpentes and Amphisbaenia, and provide a powerful tool for the reconstruction of extinct amniote ecology.

\section{Results}

\section{Convergence in lifestyle}

We reconstructed the independent primary acquisition of a fully fossorial lifestyle in 28 lepidosaur lineages.
Within the Dibamidae, pygopodid Gekkota, Lacteribaenia, Anguimorpha, and at the base of the Serpentes, we identified one acquisition each. A fully fossorial lifestyle further evolved thrice in the Gymnophthalmidae while the Scincoidea underwent 20 independent acquisitions (Fig. 1; for a high resolution version of Fig. 1, see Additional file 3). Moreover, we reconstructed reversions to a non-fullyfossorial lifestyle as comparatively rare events, only to be observed in the water skink Eulamprus, in the long-tailed blind snake Ramphotyphlops, and at the base of alethinophidian (i.e. 'non-blind') snakes. Within the latter, we found 26 secondary acquisitions of a fully fossorial lifestyle (Fig. 1) and three further reversions.

\section{Lifestyle signal in skull roof microanatomy and morphology}

Fully fossorial taxa were found to consistently exceed semi- and non-fossorial taxa in skull roof compactness along the whole cranial profile (Fig. 2b). Regarding skull roof thickness, a difference between lifestyles prevails only in the profile's anterior half (Fig. 2c). Our phylogenetically informed ANOVAs revealed that fully fossorial taxa exceed non-fossorial taxa in skull roof compactness $(p=$ $0.0009)$, thickness $(p=0.0003)$, overlap $(p=0.0003)$, and elongation $(p=0.04)$, while they consistently exhibit a smaller $r f p(p=0.0006)$ and skull diameter $(p=0.001$, Fig. 3a-f). Similarly, fully fossorial taxa were found to exceed semi-fossorial taxa in skull roof thickness $(p=0.001)$, overlap $(p=0.001)$, and elongation $(p=0.04)$ while they exhibit a smaller $r f p(p=0.001)$ and diameter $(p=0.001$, Fig. $3 \mathrm{~b}-\mathrm{f})$. Contrasting this, skull roof compactness was found not to differ between fully and semi-fossorial taxa $(p=0.117$, Fig. 3a). We detected no difference regarding any traits between the non- and semi-fossorial classes (all $p \geq 0.12$ ). The extinct Lacertibaenia resemble the fully fossorial amphisbaenian crown group regarding their skull roof compactness and, with the exception of $+C$. hassiaca, regarding their skull roof thickness and bone overlap. However, neither skull elongation nor diameter appears to disclose their purported lifestyle (Fig. 3). Although their $r f p$ clearly sets the stem-amphisbaenians apart from the Lacertidae, the signal remains ambiguous with regard to the overall dataset.

\section{Convergence in skull roof microanatomy and morphology} By means of a univariate implementation of the convergence index $\mathrm{Cl}$-i.e. the similarity between taxa in comparison with that of their ancestors, proposed by Stayton [45] as an index for the identification and quantification of convergent evolution-we detected a pronounced convergence in skull roof compactness (univariate $C 1=$ $\left.0.81, p_{C 1}<0.0001\right)$. A moderate to weak convergence was found in skull diameter, elongation, and $r f p$ (univariate $\left.C 1 \geq 0.44, p_{C 1}<0.002\right)$. No significant convergence 


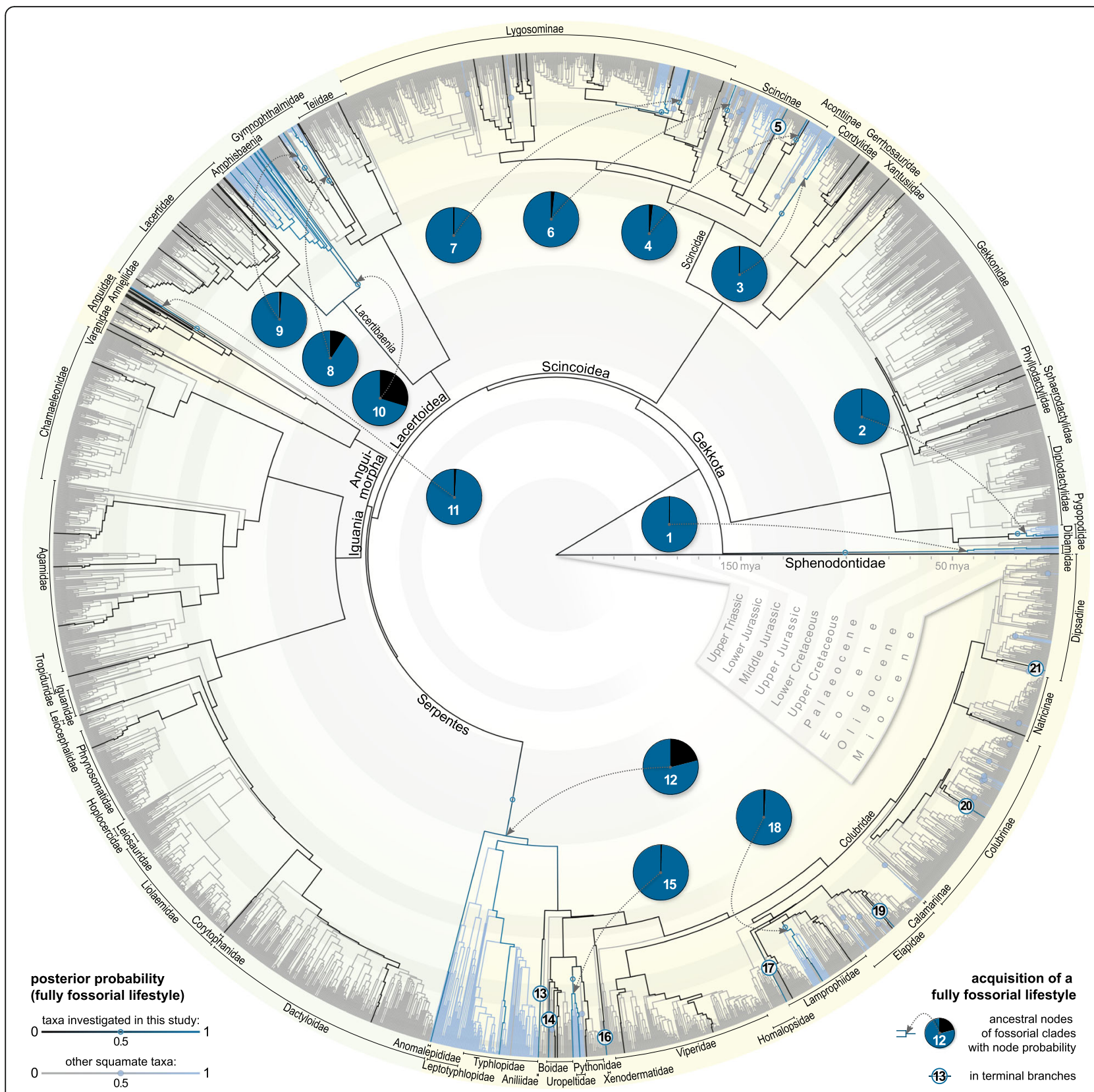

Fig. 1 Reconstruction of the acquisition of a fully fossorial lifestyle among lepidosaurs. Non-fossorial lifestyle branches are in grey/black, fossorial ones (as indicated by node posterior probability over 50\%) in light blue/dark blue. Phylogeny based on Pyron, Burbrink, and Wiens [41] with a time-calibration in accordance with Ramm et al. [42]. Additional lifestyle data obtained from Bars-Closel et al. [43]. Stochastic character mapping with phytools package [44]. For the taxa further investigated in this study (dark blue/black), the acquisition of a fully fossorial lifestyle is indicated by the numbers 1-21 (see Additional file 1: Table $\mathbf{S 4}$ for taxon names). These cover $85 \%$ of primary and $35 \%$ of secondary acquisitions in the major lepidosaur clades. For a high resolution version of Fig. 1, see Additional file 3

was detected in skull roof thickness and bone overlap (univariate $C 1 \leq 0.36, p_{C 1}>0.05$ ). The number of convergence events (i.e. univariate $C 5$ [45];), on the other hand, appears to reflect the evolution of a fully fossorial lifestyle less consistently (Additional file 1: Table S1, Fig. 4) $[46,47]$, with only moderately informative univariate C5-values for elongation and diameter (univariate C5 $\leq$ $\left.18, p_{C 5}<0.0001\right)$ and insignificant results for thickness, overlap, and $r f p\left(p_{C 5}>0.15\right)$. Only compactness (univariate $C 5=25, p_{C 5}<0.0001$ ) defines a morphospace distinguishing all clades with fully fossorial acquisitions (together with a few other clades) from the rest of the sampled lepidosaurs. In concert with the confined morphospace dimensions and the directionality of the mean 


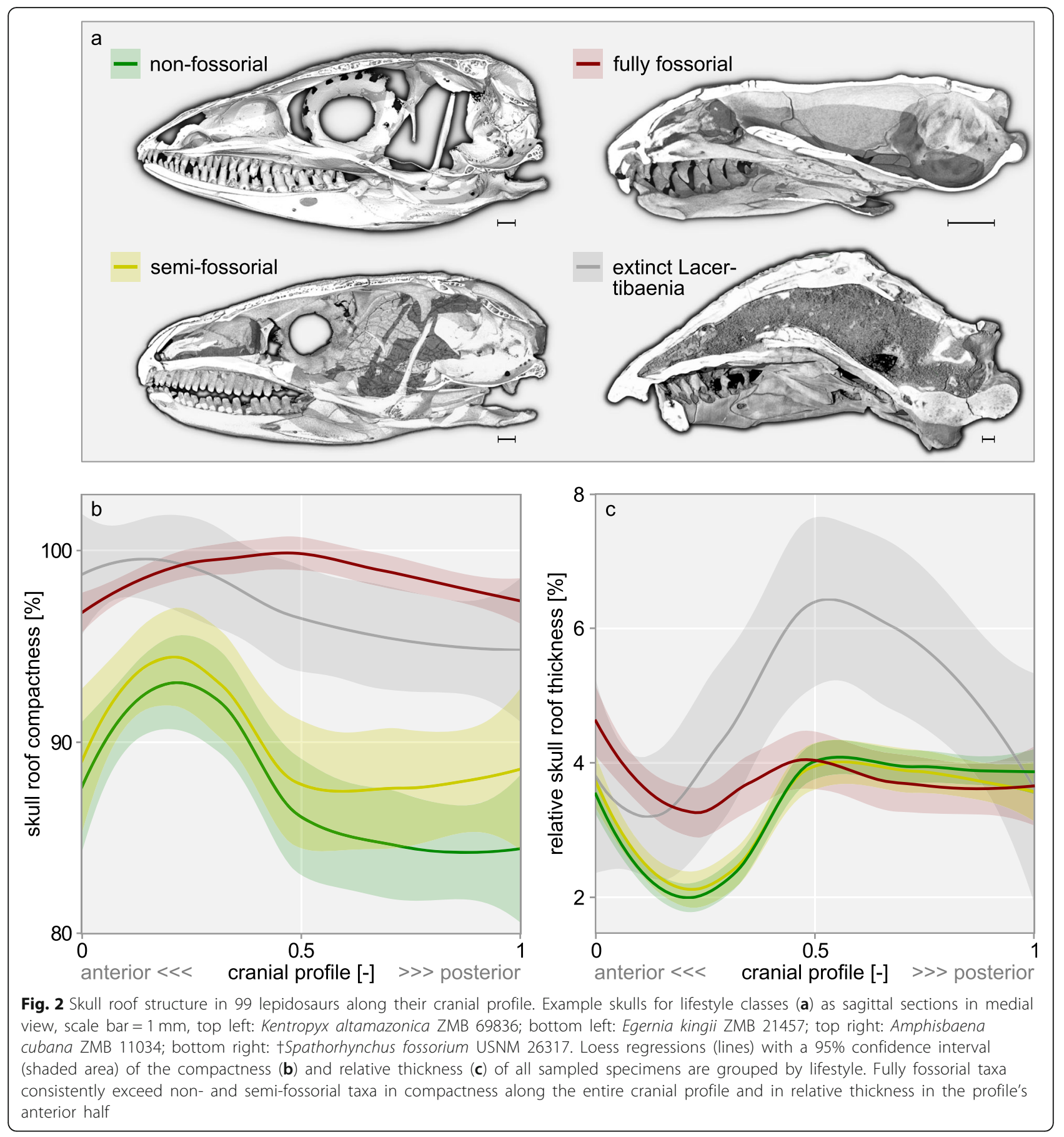

converging vectors (Fig. 4a), this confirms the exceptional role of skull roof compactness as a convergently evolved fossorial modification.

We consequently reconstructed the evolution of skull roof compactness in order to better understand its interrelation with lifestyle (Fig. 5). The trait increased independently in all lineages that primarily evolved a fully fossorial lifestyle, with the exception of the sandfish Scincus scincus. Remarkably, we also observed an increase in skull roof compactness in several semi-fossorial, limb-reduced taxa, such as Burton's legless lizard Lialis burtonis, the dwarf three-toed slider Lerista timida, some spectacled lizards of the family Gymnophthalmidae, and glass lizards of the subfamily Anguinae. In a few cases, such as in the Cuban bromeliad geckolet Sphaerodactylus bromeliarum, an increase in skull roof compactness was detected despite the absence of a fossorial lifestyle. Contrasting this, the majority of non- and 

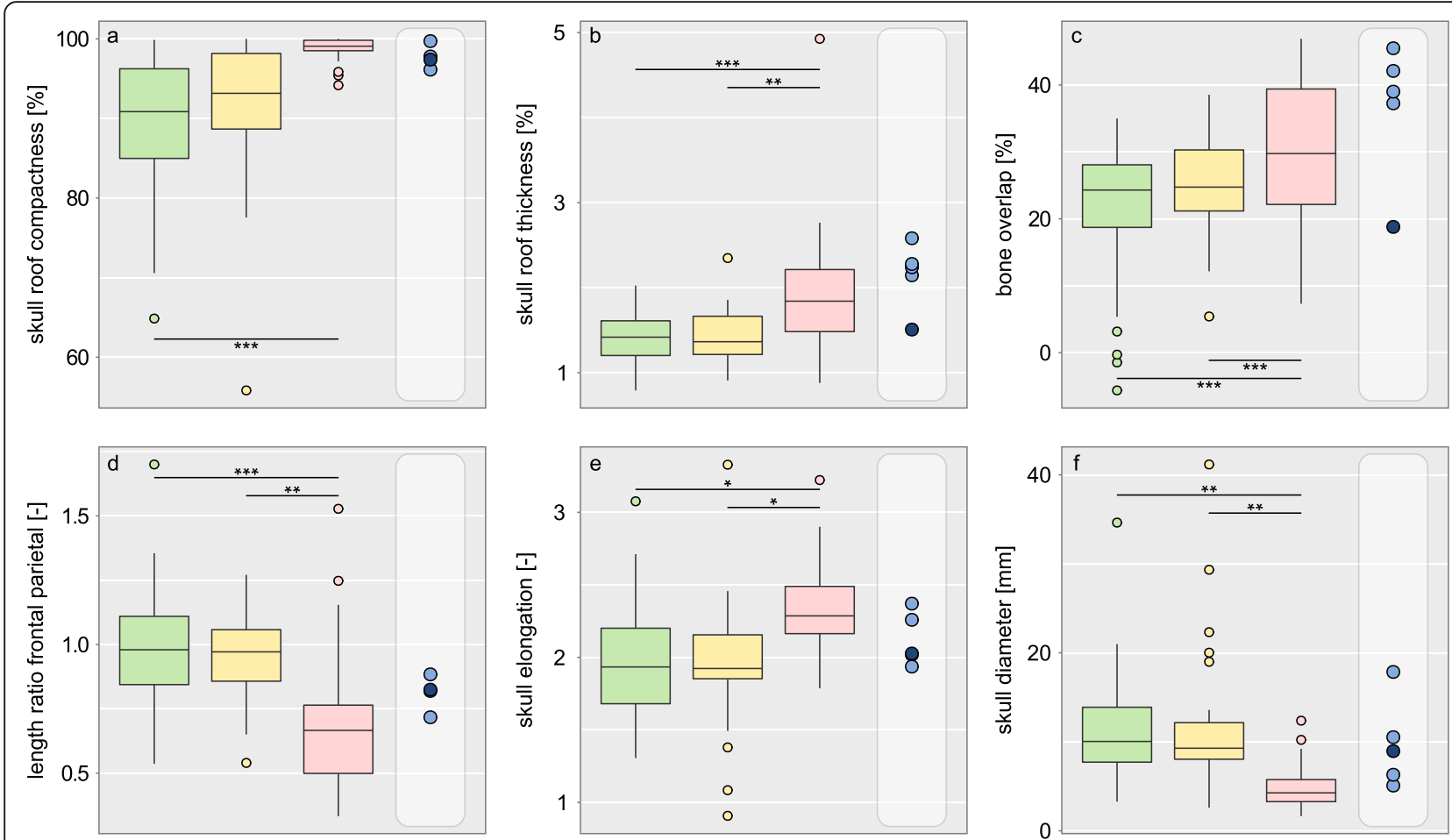

extant ecology: $\square$ non-fossorial

semi-fossorial

fully fossorial

fossils: $\quad$ extinct rhineurid

C. hassiaca

Fig. 3 Microanatomical and morphological skull roof traits compared among lifestyle classes. Compactness (a), thickness (b), overlap (c), length ratio of frontal and parietal (d), elongation (e), and diameter (f). Horizontal bars show significant differences as indicated by phylogenetically informed ANOVAs (with adjusted $p$ values $* 0.05,{ }^{* *} \leq 0.01$, and ${ }^{* *} \leq 0.001$ ). Comparison with extinct Lacertibaenia in light grey column

semi-fossorial taxa maintained a comparatively low skull roof compactness, with the strictly non-fullyfossorial Iguania exhibiting the lowest skull roof compactness in our dataset. Furthermore, the limbed water skink Eulamprus quoyii shows a decrease in skull roof compactness in concert with a reversion to a nonfossorial lifestyle. In snakes, lifestyle reversions appear to be less consistently reflected by skull roof microanatomy, with $50 \%$ of serpent taxa maintaining a high skull roof compactness after the return to a non- or semifossorial lifestyle. On the other hand, in seven out of nine serpent taxa, a secondarily acquired fully fossorial lifestyle is accompanied by a comparatively high skull roof compactness (also mostly exceeding the reconstructed basal serpent condition).

A multivariate assessment revealed that compactness preponderantly explains the observed variation in skull roof structure as the highest loaded variable in $P C 1$, which represents $62.1 \%$ of the total variance (Additional file 1: Fig. S1, Additional file 1: Table S1). The fully fossorial morphospace is comparatively confined and indicative of a small skull diameter, pronounced elongation, low $r f p$, and high skull roof compactness. Of the 59 extant taxa that fall within its limits, ten are semi-fossorial and 17 are of a non-fossorial lifestyle. It is noteworthy that, of these, $80 \%$ and $35 \%$ exhibit a serpentiform bauplan, respectively. The extensive morphospaces representing a non- and semi-fossorial lifestyle show a large overlap between one another and with the fully fossorial taxa. With the exception of the comparatively large +Spathorhynchus fossorium, all sampled extinct Lacertibaenia were found to fall within the fully fossorial morphospace.

\section{Size-effect and clade history}

In order to investigate the possible effects of constraints beyond fossoriality, we tested skull roof microanatomy and morphology for a size correlation and computed their phylogenetic signal. In the overall dataset, we found that compactness $(p=0.002)$, overlap $(p=0.004), r f p$ $(p=0.01)$, and elongation $(p=0.002)$ correlate with size, while only skull roof thickness appears to lack this correlation $(p=1.00)$. However, a within-class analysis revealed no significant differences within the lifestyle subsets (Additional file 1: Table S1), with the exception of compactness and skull elongation in semi-fossorial taxa $(0.02 \leq p \leq 0.04)$. This suggests that a size effect may not go beyond that of a possible secondary signal in the 

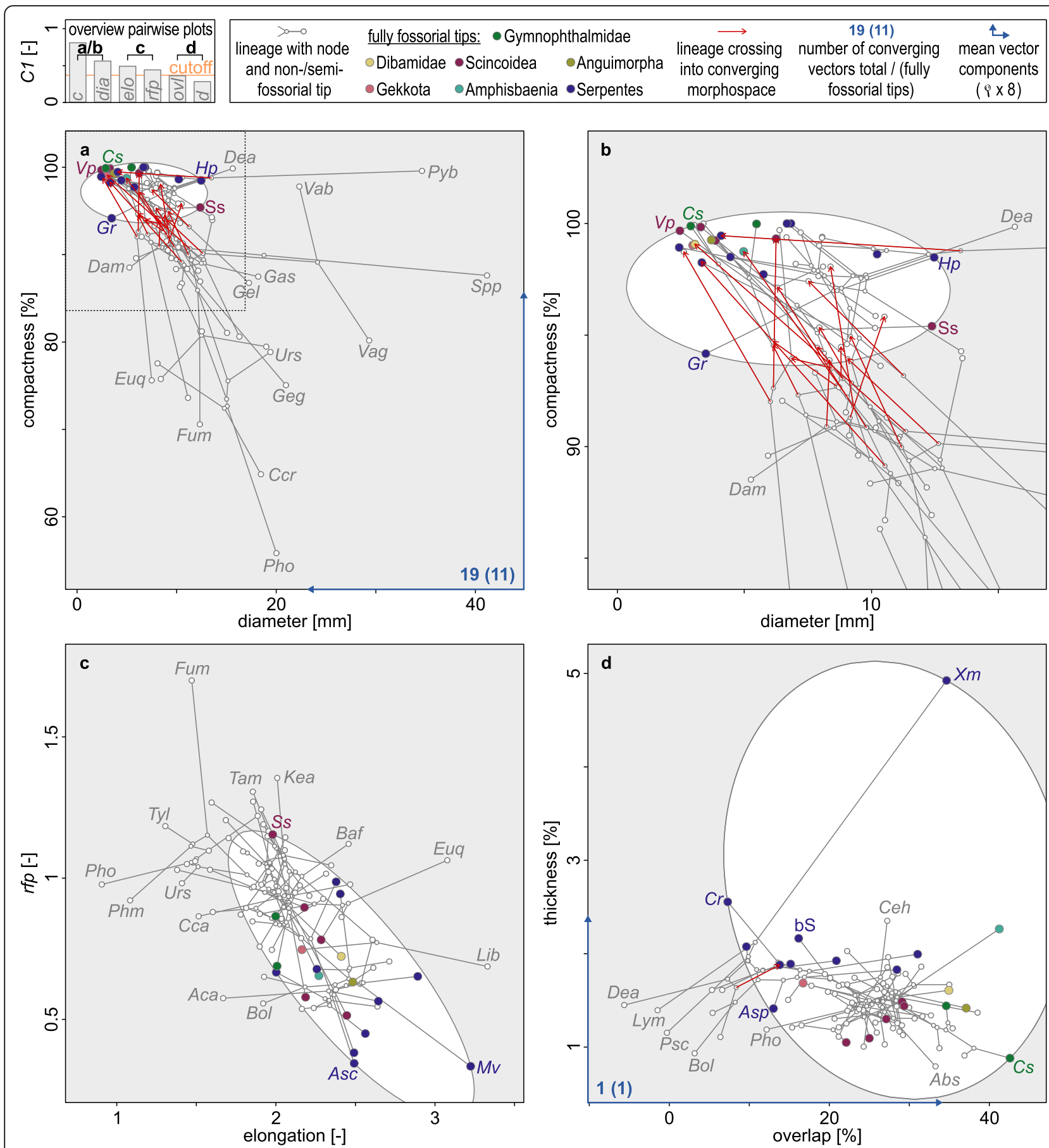

Fig. 4 Bivariate morphospaces depicting the convergent evolution of skull roof traits. Converging morphospace ellipsoids are defined by the phenotype of the fully fossorial clades (coloured tips). The convergence index C5 [45] corresponds to the number of lineages entering this space. As indicated by univariate $\mathrm{Cl}$ (see top left legend box diagram), compactness and diameter (a, b) are strongly converging - with (b) showing an enlarged excerpt of (a) in accordance with the dashed line. The ratio of frontal and parietal $r f p$ and elongation (c) are weakly converging, while overlap and thickness (d) are not converging. For key to tip abbreviations, see Additional file 1: Table S6

context of the observed lifestyle-size correlation (Fig. 3f). Comparatively strong phylogenetic signals were detected for skull roof compactness, bone overlap, $r f p$, cranial elongation, and skull diameter $(\lambda \geq 0.66$, Additional file 1 :
Table S1). The phylogenetic signal for skull roof thickness was found to be less pronounced $(\lambda=0.38)$. In accordance with these observations, we found that lifestyle classes were moderately aggregated within the phylogeny 


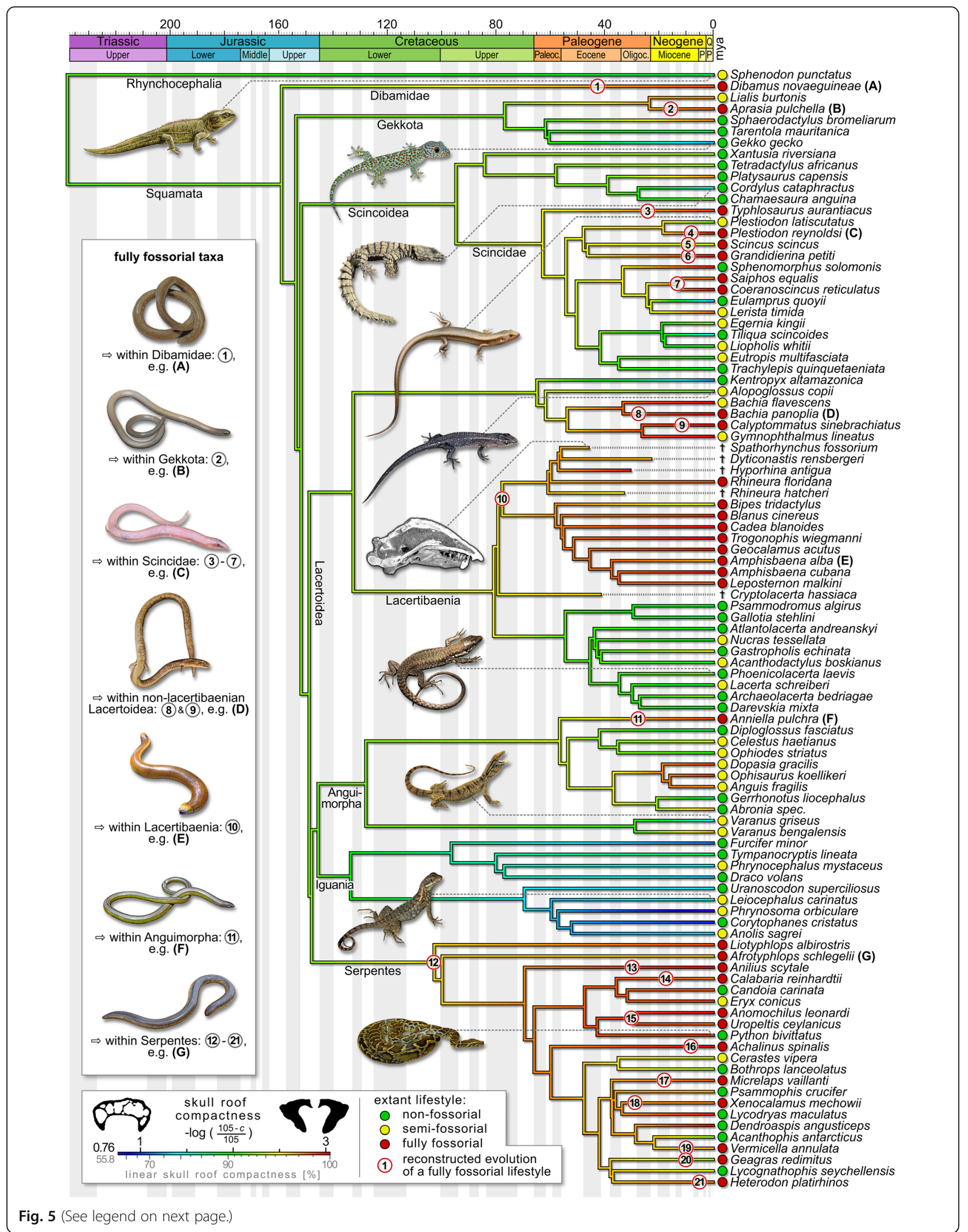


(See figure on previous page.)

Fig. 5 Reconstructed evolution of skull roof compactness in lepidosaurs. Phylogeny based on Pyron, Burbrink, and Wiens [41] with a time-

calibration in accordance with Ramm et al. [42] pruned to the sampled taxa. Continuous trait mapping was performed with maximum likelihood (phytools package [44]). Tree was supplemented with stratigraphy (strap package [48]) and visualisation of selected taxa [180-194]. Reconstructed evolution of fossoriality is indicated in accordance with complete phylogeny (Fig. 1)

$(R I=0.42, r-P L S=0.37)$. This suggests a possible collateral effect of clade history on cranial microanatomy and morphology despite their clear lifestyle signals.

\section{Discussion}

\section{Skull microanatomy and morphology as lifestyle correlates}

Our findings provide the first comprehensive evidence that fully fossorial lepidosaurs exhibit a thick and highly osteosclerotic (i.e. compact) skull roof, strongly overlapping cranial bones, and a small skull diameter (Fig. 3). Consistent with previous qualitative mention for specific lepidosaur subdivisions $[18,25,32,38,39]$, the here identified lifestyle signals indicate that these traits may concern the whole diversity of lepidosaurs as fossorial modifications. We also confirm the prevalence of an elongate cranium and low $r f p$ (i.e. elongate parietal) in fully fossorial lepidosaurs (Fig. 3) in accordance with a previous largescale skull morphology study [40]. Of these traits, we identified skull roof compactness, skull diameter, $r f p$, and cranial elongation as convergently evolved in various fully fossorial lepidosaur lineages (Additional file 1: Table S1, Fig. 4). Our findings thus complement the postcranial convergences known in burrowing lepidosaurs [18, 20, 37]. The absence of convergence in skull roof thickness and bone overlap (Fig. 4) suggests that these two traits may reflect lifestyle less consistently.

In accordance with previous descriptions of head-firstburrowing techniques $[25,31,32]$, the limitation of a lifestyle signal in skull roof thickness to the anterior half of the cranium (Fig. 2) suggests that burrowing strain is mostly directed at this region. The posterior half of the cranium, on the other hand, exhibits thick layers of epaxial and mandibular muscles in fossorial taxa [39], which may provide additional reinforcement and set limits to bone thickening in favour of a small skull diameter. The latter is constrained through its overproportionate effect on burrowing work [25]. The epaxial adductor may also explain the parietal elongation, i.e. low $r f p$, in fully fossorial taxa (Fig. 3d), since this muscle (of particular significance to head-first burrowing [25]) attaches along the parietal crest [39]. An elongated parietal further contributes to the cranial elongation typical of fossorial lepidosaurs (Fig. 3e). In analogy to the hydrodynamics of a streamlined body, this modification may reduce drag [64] during a locomotion through a fluid-like, sandy substrate [65]. Elongation may further provide a certain degree of geometry-induced rigidity
$[66,67]$ against axial forces. Additional reinforcement may result from bone overlap (Fig. 3c) since the single overlapping layers contribute to total skull roof thickness and sutures facilitate stress dissipation $[68,69]$. A more pronounced overlap may also favour deeper interdigitations and more complex suture lines. Since these features are known in some but not all fossorial lepidosaurs [39, 70], future research should address cranial joint configuration and its biomechanical implications in this context. Cooperative effects on cranial biomechanics could explain why the abovementioned modifications are often observed in concert.

Since the here investigated traits do not discriminate between non- and semi-fossorial taxa (Fig. 3), we conclude that high constraints must act on cranial microanatomy and morphology in association with a fully fossorial lifestyle which appear to differ significantly from those of a semi-fossorial lifestyle. The extensive and strongly overlapping non- and semi-fossorial morphospaces in our PCA confirm that these taxa have a rather generalist skull roof structure (Additional file 1: Fig. S1). This may be explained by the absence of head-first burrowing in the majority of our sampled semi-fossorial taxa, a technique typical of limb-reduced forms [35, 71]. Contrasting this and supporting the high constraints associated with this lifestyle, little disparity was found in the fully fossorial morphospace. However, there is a significant overlap with the non- and semi-fossorial morphospaces. Remarkably, more than half of the non-fully fossorial taxa found in this region are limb-reduced. This suggests that limblessness may co-affect skull roof morphology and microanatomy. While it is tempting to assume that the absence of limbs adds to the constraints acting on the skull by means of its use as a substitute tool, such cranial functions remain under-explored issues [72].

\section{The exceptional role of skull roof compactness}

We demonstrated the exceptional role of skull roof compactness as a lifestyle correlate with its unambiguous lifestyle signal (Fig. 3a), its strong convergence (Fig. 4), and its preponderant contribution to PC1 (Additional file 1: Table S1). In a reconstruction of trait evolution, we retraced how skull roof compactness independently increased in all lineages that primarily evolved a fully fossorial lifestyle (Fig. 5). As the only exception, S. scincus may not be considered head-first-burrowing in sensu stricto since it employs its limbs in a highly specialised swimming motion for the displacement of substrate [65]. 
A compact skull roof was also found in several semifossorial, limb-reduced pygopodid, scincoid, gymnophthalmid, and anguid taxa. Consistent with the insignificant differences between the fully and semi-fossorial classes in our ANOVA (Fig. 3a), this implies that skull roof compactness may be subject to strong constraints associated with even moderate strain exerted on the cranium. The frequent head-first penetration of moderately resistant substrates may provide an explanation. Contrasting this, most non-fossorial and limbed semifossorial taxa were found to maintain a low skull roof compactness. Moreover, the case of E. quoyii suggests that skull roof microanatomy (in non-serpent lepidosaurs) may return to a less compact state as soon as the constraints of a fossorial lifestyle are abandoned. As a general pattern, these findings demonstrate the interrelation of a primarily evolved fully fossorial lifestyle and a compact skull roof. Despite different underlying biophysics, they parallel the postcranial bone mass increase prevailing in aquatic tetrapods $[11,12]$. The knowledge of such microanatomical correlates allows retracing historic lifestyle transitions $[7,13]$ and may thus contribute to the discussion regarding the ecological origin of various reptilian lineages.

\section{Amphisbaenian fossorial modifications}

We reconstructed the oldest non-serpent acquisition of a fully fossorial lifestyle in the common ancestor of the Amphisbaenia (Fig. 1). A progressively increasing skull roof compactness clearly sets this clade apart from its non- and semi-fossorial sister-taxon, the Lacertidae. Despite varying burrowing techniques [31], we found no differences between keel-, spade-, and round-snouted amphisbaenian skull morphologies. We also found no indication for a repeated evolution of fossorial modifications within the clade [35]. On the contrary, we reconstructed a partial reversion to a less compact skull roof in Bipes tridactlyus (Fig. 5). As the only amphisbaenian genus, Bipes possesses forelimbs that it uses to excavate a tunnel entry [73], thus possibly reducing cranial strain during this stage of burrowing. Should these aspects be truly interrelated, our findings may support the possibility of a limb re-emergence from a dormant developmental program [74] in this genus as a more parsimonious alternative to a convergent limb reduction in other lineages [35]. On the other hand, the limbed stemamphisbaenian $+C$. hassiaca demonstrates that fossorial adaptations in the cranium may have evolved early in their clade history and likely predate postcranial modifications, such as limb loss [75]. Although skull roof thickness, elongation, and diameter (Fig. 3) suggest an intermediate lifestyle between lacertid lizards and amphisbaenians, $+C$. hassiaca falls within the fully fossorial morphospace in the PCA (Additional file 1: Fig.
S1). In particular, skull roof compactness and $r f p$ support its ecological comparability with the amphisbaenian crown group (Fig. 3a, d). Consistent with previous qualitative mention in the literature [70], the fossil rhineurids complement these early fossorial modifications with an increased skull roof thickness and bone overlap (Fig. 3b, c). These findings could suggest that a compactness increase preceded other acquisitions during amphisbaenian evolution. They further demonstrate the applicability of our method on fossil taxa, thus potentially elucidating the evolutionary and ecological history of extinct amniotes.

\section{Serpent fossorial modifications}

The ecological origin of snakes is highly contentious [40, $76,77]$. We reconstructed their transition to a serpentiform bauplan through a fully fossorial lineage in the lower Cretaceous (Fig. 1). Although this contradicts a recent large-scale study [40], a fossorial serpent origin is consistent with previous inferences from cranial and inner ear morphology [77, 78], ecology and habitat use [79], ecomorph evolution [20], Hox gene expression [80], and the fossil record [81, 82]. Fossoriality, however, may be considered an evolutionary dead-end [83], as implied by low diversification rates [43] and rare reversions to other lifestyles in lepidosaurs (Fig. 1). As one explanation, fossorial taxa are constrained to a small skull diameter [20], which limits prey size [84]. The evolution of macrophagy may thus be considered a key innovation that fuelled serpent evolution [85] since the loss of fossoriality in the common ancestor of alethinophidian snakes (Fig. 1). Radiation then produced roughly 3800 extant serpent species [24] of diverse ecologies [43], among them 26 lineages that secondarily acquired a fully fossorial lifestyle-presumably facilitated by ecomorph persistence. However, historical contingency [86] may have created slightly deviating fossorial modifications in these taxa. This is supported by the rather unspecific C5-indices (Fig. 4): converging morphospace outer limits are mostly $(82 \%)$ defined by alethinophidian snakes (and S. scincus). When the fully fossorial class is redefined as limbless taxa that primarily evolved a fully fossorial lifestyle (Additional file 1 : Fig. S2) [45], the morphospaces become noticeably more confined (by $76.3 \% \pm 12.7 \%$ ). For the trait pair compactness-diameter (strongly converging according to univariate $C 1$ ), the resulting number of fully fossorial lineages converging (C5) in proportion to the total number of fossorial taxa is thus increased from $52 \%$ ( 11 of 21 , Fig. $4 a$, b) to $100 \%$ (14 of 14, Additional file 1: Fig. S2). We conclude that there may be deviating constraints that act on the cranial microanatomy and morphology in alethinophidian snakes and S. scincus.

Specifically, we observed that $50 \%$ of the sampled alethinophidian snakes maintained a highly compact skull roof 
despite their reversion to a non- or semi-fossorial lifestyle (Fig. 5). These serpents may underlie constraints similar to those discussed for limbless lepidosaurs in general. This finding further complements reports on a uniform bone mass increase indiscriminate of lifestyle in the serpent postcranium $[8,22]$. Future research should therefore clarify if systemic bone mass increase [87] may be responsible for this pattern. Secondly, snakes dominate the morphospace indicative of a low skull bone overlap $(<20 \%)$ in our convergence analysis, while even distinctly fossorial snakes fall short of the pronounced overlap seen in fossorial nonserpent lepidosaurs (Fig. 4d). A reason may be that alethinophidian snakes employ radically different jaw mechanics in the context of macrophagy, including a prokinetic joint between the nasal, frontal, and prefrontal bones [88]. Although alethinophidian fossorial snakes tend to revert their kinetic skull during the secondary acquisition of a fossorial lifestyle [85], our results demonstrate that this reversion may be incomplete. Thirdly, snakes account for nine of the ten thickest skull roofs (relative to skull size) in the sampled fully fossorial taxa (Fig. 4d), which may be interpreted as an alternative serpent response to a fossorial lifestyle. These altered evolutionary pathways may explain why skull roof thickness and overlap appear to lack a significant convergence in the overall dataset.

\section{Constraints beyond fossoriality}

We considered a possible size effect on skull roof structure but found no correlation between skull diameter and skull microanatomy or morphology within the respective lifestyle classes. As the only exceptions, elongation and compactness were found to be size-correlated in the semi-fossorial class. This, however, should not be overemphasised since this class comprises strongly deviating burrowing techniques, as also indicated by the pronounced microanatomical and morphological disparity found here (e.g. Fig. 3f). Contrasting this, the sizecorrelations identified in the overall dataset can be explained by the presence of a lifestyle signal in our size proxy (Fig. 3f). The size correlation may thus not exceed the effect of this secondary signal. This, however, does not rule out constraints in miniaturised species, such as in S. bromeliarum. As the smallest non-fossorial specimen in our dataset $(S V L=24 \mathrm{~mm}$ [89], also smaller than $72 \%$ of the fossorial taxa), it exhibits the thinnest skull roof in absolute terms $(46 \mu \mathrm{m})$. This approaches the typical linear osteocyte dimensions in lepidosaurs (5$20 \mu \mathrm{m}[22,178,179])$. Thinner bone may thus require an acellular organisation, as known from delicate teleost bones [90]. In the skull roof of S. bromeliarum, this may pose a lower limit to the inclusion of cavities. Skull roof microanatomy in miniaturised taxa should therefore be further investigated.
Finally, we detected comparatively strong phylogenetic signals for most of the here investigated traits. This may partially result from the detected lifestyle aggregation in the phylogeny (e.g. the absence of fossoriality in the Iguania and Lacertidae but fossorial niche conservatism [91] in the Amphisbaenia). While feeding mechanics appear not to affect the skull morphology in non-serpent fossorial lizards [92], macrophagy and limblessness may constitute serpent-specific constraints (as discussed in the previous subsection). Our findings imply that the lifestyle signal in lepidosaur skull morphology and microanatomy may not be viewed in isolation from constraints associated with clade history and lifestyle aspects beyond fossoriality, such as miniaturisation.

\section{Conclusion}

We identify here a case of convergent evolution that concerns the whole diversity of lepidosaurs: a highly osteosclerotic (i.e. compact) skull roof, small skull diameter, elongate cranium, and low length ratio of frontal and parietal were repeatedly acquired in concert with a fully fossorial lifestyle. Foremost, skull roof compactness plays an exceptional role as a complement to the known microanatomical lifestyle correlates in tetrapods [3-5, $11,12,15,16]$ that allow a lifestyle reconstruction in extinct taxa. Our results further add to a growing body of evidence for an early evolution of fossorial modifications in the Amphisbaenia and a fossorial origin of snakes. In the latter, we also show how historical contingency associated with limblessness and macrophagy may have altered evolutionary pathways and therefore produced deviating lifestyle responses in cranial microanatomy and morphology. We thus provide insight into the evolutionary mechanisms that repeatedly shaped certain ecomorphs. Beyond the relevance of our findings for the ecological origin of the major lepidosaur lineages, a fossorial lifestyle has likely played a key role in the evolutionary history of various other tetrapod clades $[93,94]$. In the context of previously reported cranial modifications [95-97], the skull roof structure in head-first burrowing caecilians and lepospondyls may particularly deserve further investigation. The osteological lifestyle correlate presented here may thus have important implications for reconstructing lifestyle transitions and understanding their impact on the morphology and macroevolution of tetrapods in general.

\section{Methods}

\section{Specimens and lifestyle}

We sampled cranial $\mu \mathrm{CT}$ scans of 99 lepidosaur species from 13 museum collections (Additional file 1: Tables S2 and S3). An assessment of ossification level and suture closure [98] ensured that no juvenile specimens were used in the analysis. Data on taxon lifestyle was obtained from records in the literature (Additional file 1: Table S2) [23, 
27, 28, 49-63, 89, 99-155]. In accordance with previous studies [40,43, 78], we recognised three lifestyle classes defined by the degrees of fossoriality. As fully fossorial, we considered those species for which active head-first burrowing and a preponderant amount of time spent underground were reported. Species capable of excavating a burrow but most often seen above ground were considered as semi-fossorial. This class also includes limbreduced taxa that may move through a substrate that offers moderate resistance to displacement [27], such as leaf-litter. Third and most common among lepidosaurs [156], a non-fossorial lifestyle was recognised if a burrowing behaviour had not been reported for the species in question. It is noteworthy that this class also comprises limb-reduced taxa, such as grass-swimmers, that may move through microhabitats providing minor resistance to displacement [27]. Our data set thus comprises 38 nonfossorial, 24 semi-fossorial, and 32 fully fossorial species. Furthermore, we sampled exceptionally preserved fossils representing four extinct rhineurids and the stemamphisbaenian $+C$. hassiaca. A complete list of the sampled specimens, collection numbers, and lifestyle references can be found in Additional file 1: Table S2.
Cross-section extraction and overall skull measurements Cranial $\mu \mathrm{CT}$ scans were mostly acquired at the CT- \& visualisation Lab, Museum für Naturkunde, Leibniz Institute for Evolution and Biodiversity Science, Berlin, Germany with GE Phoenix Nanotom S (RRID:SCR 017995) and Yxlon FF35 CT (RRID:SCR_018208). We further included $\mu \mathrm{CT}$ scans acquired at the Helmholtz Centre Berlin for Materials and Energy and the University of Texas High-Resolution X-ray CT Facility (Additional file 1: Table S2). In accordance with specimen size, scan resolution ranged from 3.0 to $61.2 \mu \mathrm{m}$ (Additional file 1: Table S2). We focused our investigations on the medial skull roof, i.e. the premaxilla, the nasal, the frontal, and the parietal bones. With the 3D-volume processing software VG-Studio Max 3.3 (RRID:SCR 017997), we extracted two transverse cross-sections from each bone, aligned perpendicular to its dorsal surface (Fig. 6a, b). In order to take into account possible anteroposterior variations within the studied bones, we located these sections at one third and two thirds of the anteroposterior bone length. In the case of the fused frontoparietal in B. tridactylus, the corresponding positions were inferred from the average proportions in the

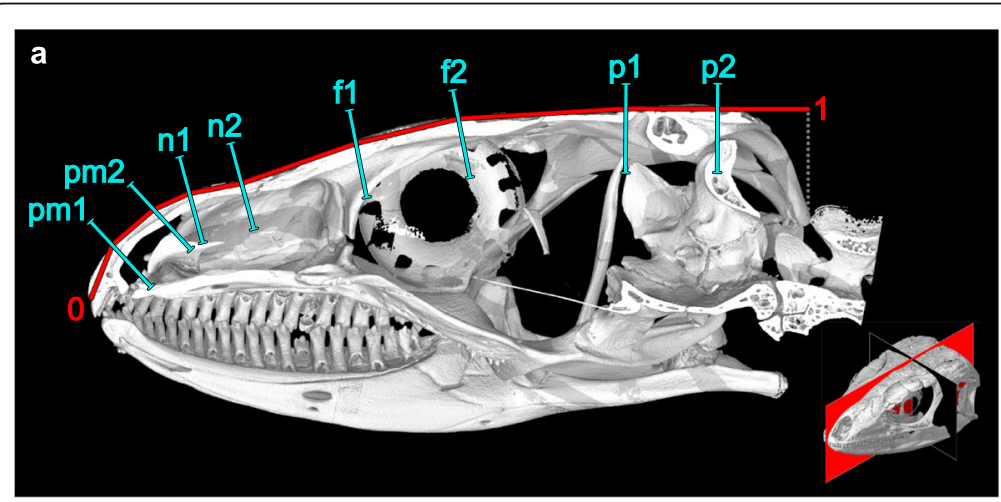

c

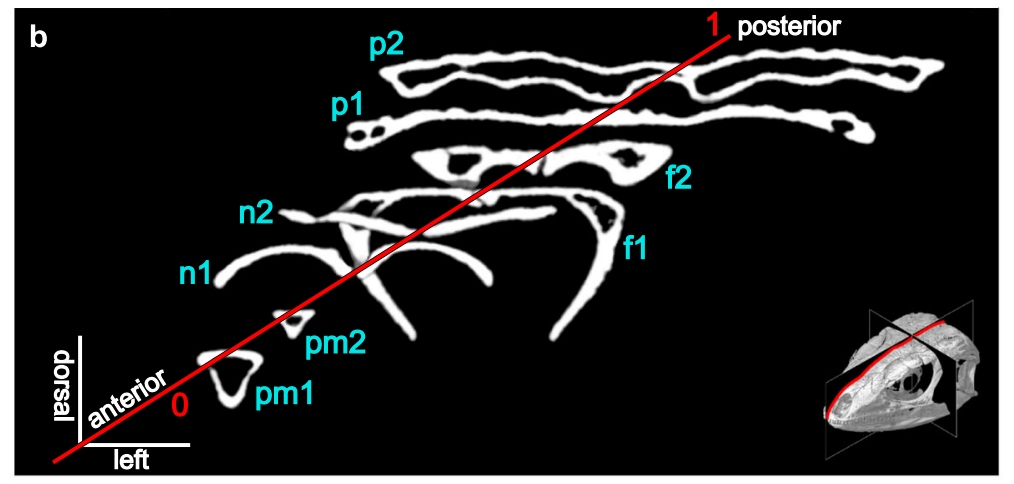

Fig. 6 Quantification of microanatomical traits. Cranial profile (red) of a lacertid lizard with skull roof cross sections (turquoise) through premaxilla (pm1/2), nasal (n1/2), frontal (f1/2), and parietal bones (p1/2). Medial view (a) of a sagittal section, isolated cross-sections (b), and single cross section (f2) as processed with ImageJ and BoneJ (c) to measure compactness and thickness. Example skulls: Gallotia stehlini ZMB 29084 (a), Darevskia mixta ZMB $44583(\mathbf{b}, \mathbf{c})$ 
amphisbaenian clade. As apparent from a comparison between the work of Gans \& Montero [39] and Evans [98], bone proportions in the lepidosaur skull roof may deviate considerably in the anteroposterior dimension (Additional file 1: Fig. S3) [39, 98]. In order to take into account these differences, we recorded each crosssection's position along an anteroposterior cranial profile. We defined these profiles as a succession of the shortest straight lines between the anterior limit of the premaxilla, the intersections between the dorsomedial bone surface and the eight respective cross-sections, and the posterior limit of the parietal (Fig. 6a, b). We further measured the linear skull dimensions, i.e. length $\left(l_{\text {cran }}\right)$, width $\left(w_{\text {cran }}\right)$, and height $\left(h_{\text {cran }}\right)$ of the cranium and articulated mandible, with the distance tool of VG-Studio Max 3.3 (RRID:SCR_017997). As our fossil specimen of $+C$. hassiaca had experienced a dorsoventral taphonomic compression, its original skull proportions were recovered in accordance with the reconstruction of Müller et al. [75]. However, bone overlap data may have become subject to distortion in the context of taphonomic fragmentation in this specimen.

\section{Microanatomical and morphological parameters}

Using the image analysis software ImageJ 1.52i (RRID: SCR_003070), we binarised greyscale tiffs with the optimise threshold function of the plug-in BoneJ 1.4.3 [157] (Fig. 6c). In a few cases, image noise and resolution required manual thresholding and partial manual segmentation of structures in close proximity to one another. In accordance with previous studies [158], bone compactness [dimensionless] was measured as the ratio between the number of pixels defining bone tissue and the total number of pixels inside the outer bone limits (Fig. 6c). We then plotted a LOESS regression [159] of the compactness values against the cross-section positions along the cranial profile (Fig. 2b). Since compactness appeared to differ consistently between the lifestyles along the entire length of the profile, we computed the arithmetic mean of the compactness $(c)$ retrieved from the eight cross-sections of a specimen. In order to assess the overall bone thickness, we computed the mean thickness $[\mathrm{mm}]$ using the local thickness function provided with BoneJ 1.4.3 [157] after filling all inner cavities (Fig. 6c). Examples of individual specimen thickness and compactness profiles can be found in Additional file 1: Fig. S5 to S7. In order to infer the anteroposterior bone overlap (ovl), we employed the following equation:

$$
\operatorname{ovl}[\%]=\frac{\frac{L_{A}+L_{B}}{2}-\left(\Delta+\frac{L_{A}}{6}+\frac{L_{B}}{6}\right)}{\frac{L_{A}+L_{B}}{2}}=\frac{2}{3}-\frac{2 \Delta}{L_{A}+L_{B}},
$$

with $\Delta$ representing the distance between the posterior cross-section of the anterior neighbouring bone $A$ and the anterior cross-section of the posterior neighbouring bone $B$-and not the distance between the neighbouring bone limits-hence enabling to compute ovl from the recorded cross-section positions along the cranial profile. The overlap thus considered both the length $L$ of the neighbouring bones and their position towards one another. An overlap of $100 \%$ corresponds to a fully centred alignment of two roofing bones in the anteroposterior dimension while an overlap of $0 \%$ was defined as the anterior limit of $B$ sharing an identical position with the posterior limit of $A$ on the anteroposterior profile. For an interspecific comparison, we calculated the arithmetic mean of the respective three overlapping regions, i.e. premaxilla-nasal, nasal-frontal, and frontal-parietal. Our assessment did not discriminate between dorsoventral, laterolateral, or interdigitated forms of overlap. Since previous studies reported a rapid evolution of frontal and parietal proportions in fossorial lepidosaur taxa [40], we further computed the length ratio $(r f p)$ between these two bones:

$$
r f p[-]=\frac{L_{\text {frontal }}[\mathrm{mm}]}{L_{\text {parietal }}[\mathrm{mm}]} .
$$

\section{Size correction and thickness integral}

A small body size is believed to be a typical concomitant of a fossorial lifestyle [18, 25]. It follows that (1) size needs to be tested for convergent evolution in accordance with lifestyle; (2) if such correlation is present, an exclusion of the size effect through consideration as a covariate in our models could create spurious effects (non-independence of covariate and independent variable); so (3) the exploration of other means for taking size into consideration would appear desirable in order to allow for an interspecific comparison. Given the various degrees and modes of body elongation [160, 161], snout-vent- or body-length may be questionable descriptors for size comparisons between lepidosaurs, while an estimation of body mass (e.g. as proposed by Feldman et al. [162]) would have added another level of potential error to our considerations.

We therefore investigated the suitability of the cranial dimensions as a reference for size correction. To this end, we tested for deviations in skull proportions between the lifestyle classes with a phylogenetically informed ANOVA using the lm.rrpp and pairwise functions of the rrpp package [47] and a within-group correlation structure based on the optimised Pagel's lambda value [163]. Lambda was recovered using the functions gls of the nlme package [164] and corPagel of the ape package [165] and the time-calibrated phylogeny 
[41, 42]. Its branch lengths were scaled according to the recovered lambda value with the rescale function of geiger package [166]. This transformed tree was then used for an rrpp regression with 10,000 permutations. If the recovered lambda was negative or greater than 1, its value was forced to be 0 or 1 , respectively (see similar protocol in Amson and Kilbourne [167]). All $p$ values were adjusted with the Holm method [168] using the p.adjust function of the built-in stats package.

In this exploration of skull proportions, the ratio of skull width and height was found not to differ ( $p=$ 0.096) in accordance with lifestyle, thus qualifying skull diameter (dia):

$$
\operatorname{dia}[\mathrm{mm}]=\sqrt{w_{\mathrm{cran}}[\mathrm{mm}] \cdot h_{\mathrm{cran}}[\mathrm{mm}]}
$$

as a suitable size descriptor and normalisation variable. The absolute skull roof thickness was consequently converted into a relative value $\left(d_{\text {rel }}\right)$ as a percentage of the skull diameter. Given that $d_{\text {rel }}$ was found to consistently reflect lifestyle in some but not the entire profile length (Fig. 2c), a thickness analysis in sub-regions of the skull roof appeared imperative. To this end, we calculated an integral of relative thickness over the cross-section position along the cranial profile. We did this by computing linear regressions between the relative thickness values, i.e. we interpolated the shortest straight lines between our measurements (Additional file 1: Fig. S3). This integral approach takes into account deviations in anteroposterior roofing bone proportions and positions. Skull bones and sutures are known to interact as an integrated compound in the process of stress dissipation [68, 69]. Since a thickness integral provides information on the skull roof as a functional unit, it may thus deliver more relevant values from a biomechanical perspective than the arithmetic mean. In order to assess where deviations in skull roof thickness may preponderantly occur in accordance with the defined lifestyles, we carried out a phylogenetically informed ANOVA (see above) on thickness profile subsections. The lifestyle classes were found not to differ significantly in the posterior half of their thickness profiles $(p=0.79)$. This appears consistent with the notion that the anterior cranium experiences the greatest strain during a head-first burrowing locomotion while the posterior cranium may be sufficiently stabilised by the well-developed epaxial and mandibular adductor muscles [39]. For all subsequent considerations, we thus employed the integral of $d_{\text {rel }}$ in the limits from 0 to 0.5 :

$$
d[\%]=\int_{0.0}^{0.5} d_{\mathrm{rel}},
$$

hereinafter referred to as skull roof thickness $(d)$ for reasons of convenience (Additional file 1: Fig. S3).

Our exploration of skull proportions also revealed that the lifestyle classes differed significantly in skull lengthto-width ratio $(p=0.003)$. In accordance with previous reports on skull elongation as a fossorial modification $[18,40]$, we therefore considered cranial elongation (elo):

$$
e l o[-]=\frac{l_{\text {cran }}[\mathrm{mm}]}{\operatorname{dia}[\mathrm{mm}]}
$$

i.e. the size-normalised skull length, as a separate trait to be tested for convergent evolution in fossorial taxa. We further performed a phylogenetically informed ANOVA (see above) in order to test our investigated dimensionless traits for a size correlation. We found an overall correlation in the full dataset for ovl, rfp, elo, and $c(0.002 \leq p \leq 0.012)$. However, a within-class analysis revealed no significant differences in the majority of lifestyle subsets (Additional file 1: Table S1). This suggests that the size effect does not go beyond that of a secondary signal in the context of a possible lifestyle-size correlation $[18,25]$. We therefore refrained from a sizecorrection of these traits.

\section{Phylogeny}

We used a large-scale lepidosaur phylogeny based on Pyron, Burbrink, and Wiens [41], which was timecalibrated using a penalised likelihood method in the program treePL [169]. We chose 14 calibration points following Ramm et al. [42]. In addition, we positioned the five extinct Lacertibaenia as proposed by Hipsely and Müller [91] with Mesquite 3.04 (RRID:SCR_017994). Where not otherwise noted, further tree manipulation and analyses were carried out with R 3.6.3 (RRID:SCR_001905). For our phylogenetically informed analyses, we pruned the tree to the sampled taxa with the phytools [44] and ape [165] packages. On the occasion of the absence of a sampled species in the phylogeny, we used a sister-taxon instead.

\section{Ancestral state and clustering of lifestyle}

We reconstructed the ancestral character state for lifestyle using the abovementioned phylogeny and stochastic character mapping based on a Markov chain Monte Carlo algorithm [170] with the make.simmap function of phytools package [44]. To this end, we appended the lifestyle information for 2719 additional taxa from Bars-Closel et al. [43] to our dataset and pruned the tree accordingly. These lifestyles were then binarised to form a fully fossorial class and a class comprising all non-fully-fossorial lifestyles. We subsequently visualised the posterior probability for the acquisition of a fully fossorial lifestyle obtained from 10 , 000 simulations as a continuous character with the densityMap function of phytools package [44]. A list of the 
reconstructed acquisitions can be found in Additional file 1: Table S4. In order to quantify homoplasy and clustering of fossoriality on the phylogeny, we computed the Retention Index [46] with the RI function of the phangorn package [171]. Likewise, we carried out a two-block partial least squares analysis with the two.b.pls function of the geomorph package [172], as proposed by Adams and Collyer [173] for the identification of a correlation between the phylogeny and ecological groups.

\section{Lifestyle signal and quantification of convergent evolution}

In order to detect a potential lifestyle signal in compactness, thickness, overlap, $r f p$, elongation, and diameter, we performed phylogenetically informed ANOVAs (see subsection 'Size correction and thickness integral'). Class mean values of the quantified microanatomical and morphological traits can be found in Additional file 1: Table S1. For individual specimen measurements, see Additional file 1: Table S5. We then assessed Pagel's $\lambda$ [174] as a measure of the phylogenetic signal in the investigated traits (phylosig function of phytools package [44]). We further investigated the convergent evolution of skull bone microanatomy and morphology in the context of a fully fossorial lifestyle using the framework of the convevol package [45]. For each trait we calculated the $C 1$ convergence index and $p$ value from 30,000 simulations using a univariate version of the convratsig function. The univariate $C 1$ quantifies the similarity between taxa in comparison with that of their ancestors [45]. Pronounced similarities between taxa that have derived from very dissimilar lineages thus produce large univariate $C 1$ values close to a maximum value of 1 . Rather than testing for convergence between the individual tips, we clustered the members of each converging fully fossorial clade together based on our reconstruction of ancestral lifestyle (see subsection 'Phylogeny'). We proceeded accordingly in order to exclude within-clade tests for convergence between ancestrally fossorial taxa and reduce the computational effort. We further computed the number of convergence events (C5), defined in this framework as the number of lineages entering a morphospace defined by the phenotype of the fully fossorial clades (Fig. 4), using a univariate version of the convnum function [45]. A bivariate implementation was employed for the visualisation in pairwise plots, which we complemented with the average converging vector components, i.e. the sum of all converging lineages divided by their number. We then compared our findings with a pairwise $C 5$ visualisation comprising alternative converging morphospaces. To this end, we excluded the alethinophidian snakes, which underwent a secondary acquisition of a fully fossorial lifestyle (Fig. 1), and the limbed S. scincus from the list of taxa defining the ellipsoids. Moreover, a multivariate exploration of the data was carried out with a principal component analysis [175] (princomp function of the built-in stats package) of those traits that were found to significantly converge and showed a lifestyle signal (Additional file 1: Fig. S1). Doing this, we refrained from employing a phylogenetically informed approach since the properties of a pPCA are more difficult to interpret than those of an ordinary PCA [176]. We further mapped a maximum likelihood reconstruction of the evolution of compactness with the contMap function of phytools package [44] (Fig. 5). Due to the pronounced aggregation of measurements between 95 and $100 \%$, compactness values were log-transformed in order to make differences within this interval clearer:

$$
c_{\log }=-\log \left(\frac{105 \%-c[\%]}{105 \%}\right)
$$

We dilated the conversion function horizontally by $5 \%$ (arbitrarily chosen) in order to avoid an asymptote at $100 \%$. A visualisation of the conversion scale and trait distribution is provided in Additional file 1: Fig. S4. Stratigraphy was added to the plot with the geoscalePhylo function of the strap package [48]. Where not otherwise noted, figures were compiled with ggplot2 package [177] and post-processed with InkScape 0.92.4 (RRID:SCR 014479).

\section{Supplementary Information}

Supplementary information accompanies this paper at https://doi.org/10. 1186/s12915-020-00908-y.

Additional file 1: Fig. $\mathbf{S 1}$ to $\mathbf{S 7}$ and Tables $\mathbf{S 1}$ to $\mathbf{S 6 .}$

Additional file 2. A spreadsheet with all per slice measurements and cross-section positions.

Additional file 3. High resolution version of Fig. 1.

\section{Acknowledgements}

Foremost, we thank all colleagues who contributed to data acquisition, in particular Kristin Mahlow (Museum für Naturkunde) and Jason Head (University of Cambridge). We thank Frank Tillack (Museum für Naturkunde Berlin), MO Rödel (Museum für Naturkunde Berlin), Jacques Gauthier (Yale Peabody Museum), and David Kizirian (American Museum of Natural History) for their help in the context of specimen loans. We thank Mareike Petersen (Museum für Naturkunde Berlin) and Martin Kirchner (Museum für Naturkunde Berlin) for their assistance with the MfN data repository. We thank Tristan Stayton (Bucknell University) for providing a univariate version of his convevol code. We thank Donald Davesne (University of Oxford) for communication on bone microanatomy. We thank Leonie Ringrose

(Humboldt-Universität zu Berlin) and Tobias Foskett (Forum Berufsbildung Berlin) for their linguistic and stylistic support. We thank Nadia Fröbisch (Museum für Naturkunde Berlin), Faysal Bibi (Museum für Naturkunde Berlin), John Nyakatura (Humboldt-Universität zu Berlin), and all colleagues at the Bibi-Müller-Wissensmanufaktur (Museum für Naturkunde Berlin) for their feedback on our work. Finally, we thank P. David Polly (Indiana University Bloomington) and two anonymous reviewers for their helpful proposals regarding the revision of our manuscript.

\section{Authors' contributions}

E.A., J.M., and R.E. conceived the project. C.H. contributed to CT-scanning. R.E. collected the data from the scanned volumes. T.R. and J.M. calibrated the phylogeny. T.R., R.E., and E.A. conducted the ancestral lifestyle reconstruction. E.A. and R.E. conducted all other analyses. The manuscript was written by 
R.E. and reviewed by E.A. and T.R. All authors read and approved the final manuscript.

Twitter:

Roy Ebel, @Eulamprus

Till Ramm, @Lophosaurus

Eli Amson, @AmsonEli

\section{Funding}

R.E. and T.R. would like to thank the Studienstiftung des Deutschen Volkes for funding their studies. E.A. is funded by the Deutsche Forschungsgemeinschaft (grant number: DFG AM 517/1-1). Open Access funding enabled and organized by Projekt DEAL.

\section{Availability of data and materials}

All $\mu C T$ scans supporting the conclusions of this article are curated in the public digital collection of the Museum für Naturkunde (MfN), Leibniz Institute for Evolution and Biodiversity Science, Berlin, Germany and accessible at the MfN Data Repository (https://doi.org/10.7479/4k4c-yc83). All 2D slices exported from these volumes can be found on Figshare (https:// doi.org/10.6084/m9.figshare.13084583). Further raw data, such as per slice and per specimen measurements, are provided in Additional files 1 and 2. The univariate implementation of the functions of the $R$ package convevol [45] is available on GitHub (https://github.com/eliamson/convevol1d).

\section{Ethics approval and consent to participate}

Not applicable.

\section{Consent for publication}

Not applicable.

\section{Competing interests}

The authors declare that they have no competing interests.

\section{Author details}

${ }^{1}$ Museum für Naturkunde, Leibniz Institute for Evolution and Biodiversity Science, Berlin, Germany. ${ }^{2}$ Institute for Biology, Faculty of Life Sciences, Humboldt-Universität zu Berlin, Berlin, Germany. ${ }^{3}$ School of BioSciences, The University of Melbourne, Parkville, Victoria 3052, Australia. ${ }^{4}$ Sciences Department, Museums Victoria, Carlton, Victoria 3053, Australia.

\section{Received: 3 September 2020 Accepted: 23 October 2020}

\section{Published online: 30 November 2020}

\section{References}

1. Stayton CT. What does convergent evolution mean? The interpretation of convergence and its implications in the search for limits to evolution. Interface Focus. 2015:5:20150039.

2. Currie A. Convergence as evidence. Br J Philos Sci. 2013;64:763-86..

3. Kivell TL. A review of trabecular bone functional adaptation: what have we learned from trabecular analyses in extant hominoids and what can we apply to fossils? J Anat. 2016;228:569-94..

4. Georgiou L, Kivell TL, Pahr DH, Buck LT, Skinner MM. Trabecular architecture of the great ape and human femoral head. J Anat. 2019;234:679-93.

5. Kriloff A, Germain D, Canoville A, Vincent P, Sache M, Laurin M. Evolution of bone microanatomy of the tetrapod tibia and its use in palaeobiological inference. J Evol Biol. 2008;21:807-26.

6. Canoville A, Laurin M. Evolution of humeral microanatomy and lifestyle in amniotes, and some comments on palaeobiological inferences. Biol J Linn Soc. 2010;100:384-406

7. Amson E, de Muizon C, Laurin M, Argot C, de Buffrénil V. Gradual adaptation of bone structure to aquatic lifestyle in extinct sloths from Peru. Proc R Soc B Biol Sci. 2014;281:20140192..

8. Canoville A, de Buffrénil V, Laurin M. Microanatomical diversity of amniote ribs: an exploratory quantitative study. Biol J Linn Soc. 2016;118:706-33..

9. Dumont $M$, Laurin $M$, Jacques F, Pellé E, Dabin W, De Buffrénil V. Inner architecture of vertebral centra in terrestrial and aquatic mammals: a twodimensional comparative study. J Morphol. 2013;274:570-84..

10. Hayashi S, Houssaye A, Nakajima Y, Chiba K, Ando T, Sawamura H, et al. Bone inner structure suggests increasing aquatic adaptations in Desmostylia (Mammalia, Afrotheria). PLoS One. 2013;8:32-5.
11. De Ricqlès A, De Buffrénil V. Bone histology, heterochronies and the return of tetrapods to life in water: where are we? In: Mazin J-M, de Buffrenil V, editors. Secondary adaptation of tetrapods to life in water. München: Verlag Dr. Friedrich Pfeil; 2001. p. 289-310..

12. Houssaye A. "Pachyostosis" in aquatic amniotes: a review. Integr Zool. 2009; 4:325-40.

13. de Buffrénil V, Canoville A, D'Anastasio R, Domning DP. Evolution of sirenian pachyosteosclerosis, a model-case for the study of bone structure in aquatic tetrapods. J Mamm Evol. 2010;17:101-20.

14. Biknevicius AR. Biomechanical scaling of limb bones and differential limb use in caviomorph rodents. J Mammal. 1993;74:95-107..

15. Botha J. Biological aspects of the Permian dicynodont Oudenodon (Therapsida: Dicynodontia) deduced from bone histology and crosssectional geometry. Palaeontol Africana. 2003;39:37-44..

16. Amson E, Arnold $\mathrm{P}$, van Heteren AH, Canoville A, Nyakatura JA. Trabecular architecture in the forelimb epiphyses of extant xenarthrans (Mammalia). Front Zool. 2017;14:1-17..

17. Mielke M, Wölfer J, Arnold P, Van Heteren AH, Amson E, Nyakatura JA, et al. Trabecular architecture in the sciuromorph femoral head: allometry and functional adaptation. Zool Lett. 2018;4:1-11..

18. Lee MSY. Convergent evolution and character correlation in burrowing reptiles: towards a resolution of squamate relationships. Biol J Linn Soc. 1998:65:369-453..

19. Greer AE. Limb reduction in squamates: identification of the lineages and discussion of the trends. J Herpetol. 1991;25:166-73.

20. Wiens JJ, Brandley MC, Reeder TW. Why does a trait evolve multiple times within a clade? Repeated evolution of snakelike body form in squamate reptiles. Evolution. 2006;60:123-41.

21. Benesch AR, Withers PC. Burrowing performance and the role of limb reduction in Lerista (Scincidae, Lacertilia). Senckenb Lethaea. 2002;82:10714.

22. Houssaye A, Mazurier A, Herrel A, Volpato V, Tafforeau P, Boistel R, et al. Vertebral microanatomy in squamates: structure, growth and ecological correlates. J Anat. 2010;217:715-27..

23. Vitt $L$, Caldwell JP. Herpetology: an introductory biology of amphibians and reptiles. 4th ed. London, Waltham \& San Diego: Academic Press; 2014

24. Uetz P, Freed P, Hošek J. The reptile database. 2020. http://www.reptiledatabase.org. Accessed 1 Jun 2019

25. Navas CA, Antoniazzi MM, Carvalho JE, Chaui-Berlink JG, James RS, Jared C, et al. Morphological and physiological specialization for digging in amphisbaenians, an ancient lineage of fossorial vertebrates. J Exp Biol. 2004; 207:2433-41..

26. Wu NC, Alton LA, Clemente CJ, Kearney MR, White CR. Morphology and burrowing energetics of semi-fossorial skinks (Liopholis spp.). J Exp Biol. 2015;218:2416-26

27. Barros FC, Herrel A, Kohlsdorf T. Head shape evolution in Gymnophthalmidae: does habitat use constrain the evolution of cranial design in fossorial lizards? J Evol Biol. 2011;24:2423-33.

28. Melville J, Schulte JA. Correlates of active body temperatures and microhabitat occupation in nine species of central Australian agamid lizards. Austral Ecol. 2001:26:660-9.

29. Pianka ER, Vitt LJ. Lizards: windows to the evolution of diversity. Berkeley, Los Angeles: University of California Press; 2003.

30. Auffenberg W. The Bengal monitor. Gainesville: University Press of Florida; 1994.

31. Kearney M. Systematics of the Amphisbaenia (Lepidosauria: Squamata) based on morphological evidence from recent and fossil forms. Herpetol Monogr. 2003;17:1-74

32. Gans $C$. The characteristics and affinities of the Amphisbaenia. Trans Zool Soc London. 1978;34:347-416.

33. Martín J, López P, Salvador A. Microhabitat selection of the amphisbaenian Blanus cinereus. Copeia. 1991;1991:1142-6.

34. Clark DR. Experiments into selection of soil type, soil moisture level, and temperature by five species of small snakes. Trans Kansas Acad Sci. 1967;70:4906

35. Kearney M, Stuart BL. Repeated evolution of limblessness and digging heads in worm lizards revealed by DNA from old bones. Proc R Soc B Biol Sci. 2004:271:1677-83.

36. McGhee GRJ. Convergent evolution: limited forms most beautiful. Cambridge: The MIT Press; 2011. 
37. Bergmann PJ, Morinaga G. The convergent evolution of snake-like forms by divergent evolutionary pathways in squamate reptiles. Evolution. 2019;73: 481-96..

38. Gans C. Amphisbaenians - reptiles specialized for a burrowing existence. Endeavour. 1969;28:146..

39. Gans C, Montero R. An atlas of amphisbaenian skull anatomy. In: Gans C, Gaunt A, Adler K, editors. Biology of the Reptilia 21. Ithaca: Society for the Study of Amphibians \& Reptiles; 2008. p. 621-738.

40. Watanabe A, Fabre AC, Felice RN, Maisano JA, Müller J, Herrel A, et al. Ecomorphological diversification in squamates from conserved pattern of cranial integration. Proc Natl Acad Sci U S A. 2019;116:14688-97..

41. Pyron RA, Burbrink FT, Wiens JJ. A phylogeny and revised classification of Squamata, including 4161 species of lizards and snakes. BMC Evol Biol. 2013;13:93..

42. Ramm T, Cantalapiedra JL, Wagner P, Penner J, Rödel M-O, Müller J. Divergent trends in functional and phylogenetic structure in reptile communities across Africa. Nat Commun. 2018;9:4697..

43. Bars-Closel M, Kohlsdorf T, Moen DS, Wiens JJ. Diversification rates are more strongly related to microhabitat than climate in squamate reptiles (lizards and snakes). Evolution. 2017:71:2243-61..

44. Revell L. Phytools: an R package for phylogenetic comparative biology (and other things). Methods Ecol Evol. 2012;3:217-23.

45. Stayton CT. The definition, recognition, and interpretation of convergent evolution, and two new measures for quantifying and assessing the significance of convergence. Evolution. 2015;69:2140-53.

46. Farris JS. The retention index and the rescaled consistency index. Cladistics. 1989;5:417-9.

47. Collyer ML, Adams DC. RRPP: an r package for fitting linear models to highdimensional data using residual randomization. Methods Ecol Evol. 2018;9: 1772-9..

48. Bell MA, Lloyd GT. Strap: an R package for plotting phylogenies against stratigraphy and assessing their stratigraphic congruence. Palaeontology. 2015;58:379-89.

49. Robertson P, Coventry AJ. Reptiles of Victoria: a guide to identification and ecology. Clayton South: CSIRO Publishing; 2019.

50. Chapple DG. Ecology, life-history, and behavior in the Australian scincid genus Egernia, with comments on the evolution of complex sociality in lizards. Herpetol Monogr. 2003;17:145-80.

51. Price-Rees SJ, Brown GP, Shine R. Habitat selection by bluetongue lizards (Tiliqua, Scincidae) in tropical Australia: a study using GPS telemetry. Anim Biotelemetry. 2013;1:7.

52. Catena AM, Hembree DI. Biogenic structures of burrowing skinks: Neoichnology of Mabuya multifaciata (Squamata: Scincidae). In: Experimental approaches to understanding fossil organisms. Dordrecht: Springer; 2014. p. 343-69..

53. Spawls $S$, Howell $K$, Hinkel H, Menegon M. Field guide to East African reptiles. London, New Delhi, New York, Sydney: Bloomsbury Publishing; 2018.

54. Vitt LJ, Sartorius SS, Avila-Pires TCS, Espósito MC. Life at the river's edge: ecology of Kentropyx altamazonica in Brazilian Amazonia. Can J Zool. 2001 79:1855-65..

55. Hernández-Jaimes C, Jerez A, Ramírez-Pinilla MP. Embryonic development of the skull of the Andean lizard Ptychoglossus bicolor (Squamata, Gymnophthalmidae). J Anat. 2012;221:285-302..

56. van Buurt G. Field guide to the amphibians and reptiles of Aruba, Curaçao and Bonaire. Frankfurt am Main: Chimaira; 2005

57. Martin J, López P. Influence of habitat structure on the escape tactics of the lizard Psammodromus algirus. Can J Zool. 1995;73:129-32

58. Carretero M, Roca V, Martín J, Llorente G, Montori Faura A, Santos X, et al. Diet and helminth parasites in the Gran Canaria giant lizard, Gallotia stehlini. Rev española Herpetol. 2006;20:105-17.

59. Hoser RT. Two new genera of lacertid lizards (Reptilia: Squamata: Sauria: Lacertidae) from the Middle-east. Australas J Herpetol. 2015;30:11-7..

60. Cooper WE, Whiting MJ. Foraging modes in lacertid lizards from southern Africa. Amphib Reptil. 1999;20:299-311..

61. Segniagbeto GH, Trape J-FF, Afiademanyo KM, Rödel MO, Ohler A, Dubois A, et al Checklist of the lizards of Togo (West Africa), with comments on systematics, distribution, ecology, and conservation. Zoosystema. 2015;37:381-403..

62. Zaady E, Bouskila A. Lizard burrows association with successional stages of biological soil crusts in an arid sandy region. J Arid Environ. 2002;50: $235-46$.
63. Modrý D, Necas P, Rifai L, Bischoff W, Hamidan N, Amr Z. Revision of the levantine "Lacerta" laevis / kulzeri- complex: 3. The rock lizard of Wadi ramm, Phoenicolacerta kulzeri khazaliensis ssp. N. Vertebr Zool. 2013:63:307-12.

64. Landau LD, Lifshitz EM. Fluid dynamics. 2nd ed. Oxford, Burlington: Butterworth-Heineman, Elsevier; 1987.

65. Baumgartner W, Fidler F, Weth A, Habbecke M, Jakob P, Butenweg C, et al. Investigating the locomotion of the sandfish in desert sand using NMRimaging. PLoS One. 2008;3:e3309..

66. Vella D, Ajdari A, Vaziri A, Boudaoud A. Indentation of ellipsoidal and cylindrical elastic shells. Phys Rev Lett. 2012;109:144302..

67. Lazarus A, Florijn HCB, Reis PM. Geometry-induced rigidity in nonspherical pressurized elastic shells. Phys Rev Lett. 2012;109:144301..

68. Jones MEHH, Curtis N, Fagan MJ, O'Higgins P, Evans SE. Hard tissue anatomy of the cranial joints in Sphenodon (Rhynchocephalia): sutures, kinesis, and skull mechanics. Palaeontol Electron. 2011;14:1-92..

69. Moazen M, Curtis N, O'Higgins P, Jones MEHH, Evans SE, Fagan MJ. Assessment of the role of sutures in a lizard skull: a computer modelling study. Proc R Soc B Biol Sci. 2009;276:39-46.

70. Müller J, Hipsley CA, Maisano JA. Skull osteology of the Eocene amphisbaenian Spathorhynchus fossorium (Reptilia, Squamata) suggests convergent evolution and reversals of fossorial adaptations in worm lizards. J Anat. 2016:229:615-30..

71. Gans C. Tetrapod limblessness : evolution and functional corollaries. Am Zool. 1975;15:455-67.

72. Wake MH. The skull as a locomotor organ. In: Hanken J, Hall BK, editors. The skull: functional and evolutionary mechanisms. Chicago, London: University of Chicago Press; 1993. p. 197-240..

73. Gans C, Shaw CE. The locomotion of Bipes biporus cope. Proc Annu Meet Am Soc Ichythologists Herpetol. 1963;50:38.

74. Leal F, Cohn MJ. Developmental, genetic, and genomic insights into the evolutionary loss of limbs in snakes. genesis. 2018:56:e23077.

75. Müller J, Hipsley CA, Head JJ, Kardjilov N, Hilger A, Wuttke M, et al. Eocene lizard from Germany reveals amphisbaenian origins. Nature. 2011;473:364-7.

76. Lee MSY. Molecular evidence and marine snake origins. Biol Lett. 2005;1:227-30.

77. Yi H, Norell MA. The burrowing origin of modern snakes. Sci Adv. 2015;1: e1500743..

78. Da Silva FO, Fabre A-C, Savriama Y, Ollonen J, Mahlow K, Herrel A, et al. The ecological origins of snakes as revealed by skull evolution. Nat Commun. 2018;9: 376.

79. Hsiang AY, Field DJ, Webster TH, Behlke ADB, Davis MB, Racicot RA, et al. The origin of snakes: revealing the ecology, behavior, and evolutionary history of early snakes using genomics, phenomics, and the fossil record. BMC Evol Biol. 2015;15:87..

80. M. Woltering J. From lizard to snake; behind the evolution of an extreme body plan. Curr Genomics. 2012;13:289-99..

81. Martill DM, Tischlinger $H$, Longrich NR. A four-legged snake from the Early Cretaceous of Gondwana. Science. 2015;349:416-9..

82. Longrich NR, Bhullar BAS, Gauthier JA. A transitional snake from the Late Cretaceous period of North America. Nature. 2012;488:205-8..

83. Cyriac VP, Kodandaramaiah U. Digging their own macroevolutionary grave: fossoriality as an evolutionary dead end in snakes. J Evol Biol. 2018;31:587-98.

84. Cundal D, Greene HW. Feeding in snakes. In: Schwenk K, editor. Feeding: form, function, and evolution in tetrapod vertebrates. San Diego, London: Academic Press; 2000. p. 293-333.

85. Scanferla A. Postnatal ontogeny and the evolution of macrostomy in snakes R Soc Open Sci. 2016:3:160612

86. Gould SJ. Wonderful life: the Burgess shale and the nature of history. W. W. Norton \& Company: New York, London; 1989.

87. Lieberman DE. How and why humans grow thin skulls: experimental evidence for systemic cortical robusticity. Am J Phys Anthropol. 1996;101:217-36..

88. Rieppel O. The evolution of the naso-frontal joint in snakes and its bearing on snake origins. J Zool Syst Evol Res. 1978;16:14-27..

89. Peters G, Schwartz A. Ein neuer, Bromelien bewohnender Kugelfingergecko (Gokkonidae: Sphaerodactylus) aus Oriente/Cuba. Mitteilungen aus dem Museum für Naturkd Berlin Zool Museum und Inst für Spez Zool. 1972;48: 393-9.

90. Davesne D, Meunier FJ, Schmitt AD, Friedman M, Otero O, Benson RBJ. The phylogenetic origin and evolution of acellular bone in teleost fishes: insights into osteocyte function in bone metabolism. Biol Rev. 2019;94:1338-63.. 
91. Hipsley CA, Müller J. Relict endemism of extant Rhineuridae (Amphisbaenia): testing for phylogenetic niche conservatism in the fossil record. Anat Rec. 2014;297:473-81..

92. Guilloux MLE, Miralles A, Measey J, Vanhooydonck B, Reilly JCO, Lowie A. Trade-offs between burrowing and biting force in fossorial scincid lizards? Biol J Linn Soc. 2020;130:310-9..

93. Smith R, Botha J. The recovery of terrestrial vertebrate diversity in the South African Karoo Basin after the end-Permian extinction. Comptes Rendus Palevol. 2005;4:623-36.

94. Lyson TR, Bever GS. Origin and evolution of the turtle body plan. Annu Rev Ecol Evol Syst. 2020;51:annurev-ecolsys-110218-024746..

95. Kleinteich T, Maddin HC, Herzen J, Beckmann F, Summers AP. Is solid always best? Cranial performance in solid and fenestrated caecilian skulls. J Exp Biol. 2012;215:833-44..

96. Sherratt E, Gower DJ, Klingenberg CP, Wilkinson M. Evolution of cranial shape in caecilians (Amphibia: Gymnophiona). Evol Biol. 2014;41:528-45..

97. Pardo JD, Anderson JS. Cranial morphology of the carboniferous-permian tetrapod Brachydectes newberryi (Lepospondyli, Lysorophia): new data from MCT. PLoS One. 2016;11:8-10.

98. Evans SE. The skull of lizards and tuatara. Biol Reptil. 2008;20:1-347..

99. Dawbin WH. The tuatara. Tuatara. 1949;2:91-5.

100. Rieppel O. The cranial morphology of the fossorial lizard genus Dibamus with a consideration of its phylogenetic relationships. J Zool. 1984;204:289-327.

101. Shea GM. Family Pygopodidae. In: Glasby CG, GJB R, Beesley PL, editors. Fauna of Australia - volume 2A Amphibia and Reptilia. Canberra: AGPS; 1993.

102. Johnson MK, Russell AP, Bauer AM. Locomotor morphometry of the Pachydactylus radiation of lizards (Gekkota: Gekkonidae): a phylogenetically and ecologically informed analysis. Can J Zool. 2005;83:1511-24..

103. Subramanean J, Vikram RM. Monitor lizards and geckos used in traditional medicine face extinction and need protection. Curr Sci. 2012;102:1248.

104. Fellers GM, Drost CA. Ecology of the island night lizard, Xantusia riversiana, on Santa Barbara Island, California. Herpetol Monogr. 1991;5:28-78..

105. Mason MC, Alexander GJ. Oviposition site selection in Tetradactylus africanus africanus: a relationship with the ant Anochetus faurei. African J Herpetol. 1996:45:31-7.

106. Whiting MJ, Branch WR, Pepper M, Keogh JS. A new species of spectacularly coloured flat lizard Platysaurus (Squamata: Cordylidae: Platysaurinae) from southern Africa. Zootaxa. 2015;3986:173-92.

107. Broeckhoven C, Mouton PLFN. Under pressure: morphological and ecological correlates of bite force in the rock-dwelling lizards Ouroborus cataphractus and Karusasaurus polyzonus (Squamata: Cordylidae). Biol J Linn Soc. 2014;111:823-33..

108. Shine $R$, Wall M. Interactions between locomotion, feeding, and bodily elongation during the evolution of snakes. Biol J Linn Soc. 2008;95:293-304..

109. Goris RC. The reptiles and amphibians of Hachijojima Island. Acta Herpetol Jpn. 1967;2:25-30..

110. Pike DA, Peterman KS, Exum JH. Use of altered habitats by the endemic sand skink (Plestiodon reynoldsi Stejneger). Southeast Nat. 2007;6:715-26.

111. Stadler AT, Vihar B, Günther $M$, Huemer M, Riedl M, Shamiyeh $S$, et al. Adaptation to life in aeolian sand: how the sandfish lizard, Scincus scincus, prevents sand particles from entering its lungs. J Exp Biol. 2016; 219:3597-604.

112. Rosa GM, Bergò PE, Crottini A, Andreone F. Report on the life colouration of the enigmatic burrowing skink Voeltzkowia rubrocaudata (Grandidier, 1869) from southwestern Madagascar. Bonn Zool Bull. 2012;61:31-4..

113. Rabosky DL, Donnellan SC, Grundler M, Lovette IJ. Analysis and visualization of complex macroevolutionary dynamics: an example from Australian scincid lizards. Syst Biol. 2014;63:610-27.

114. Law BS, Bradley RA. Habitat use and basking site selection in the water skink, Eulamprus quoyii. J Herpetol. 1990:24:235-40.

115. Marco A, Díaz-Paniagua C, Hidalgo-Vila J. Influence of egg aggregation and soil moisture on incubation of flexible-shelled lacertid lizard eggs. Can J Zool. 2004;82:60-5..

116. Bombi P, Salvi D, Luiselli L, Bologna MA. Modelling correlates of microhabitat use of two sympatric lizards: a model selection approach. Anim Biol. 2009;59:109-26.

117. Gabelaia M, Adriaens D, Tarkhnishvili D. Phylogenetic signals in scale shape in Caucasian rock lizards (Darevskia species). Zool Anz. 2017;268: $32-40$.
118. Ribeiro MA, Amaral S. Catalogue of distribution of lizards (Reptilia: Squamata) from the Brazilian Amazonia. III. Anguidae, Scincidae, Teiidae. Zootaxa. 2016:4205:401-30..

119. Colli GR, Bastos RP, Araujo AFB. The character and dynamics of the cerrado herpetofauna. In: Oliveira P, Marquis R, editors. The cerrados of Brazil: ecology and natural history of a neotropical savanna. New York: Columbia University Press; 2002. p. 223-239..

120. Thomas R. A new species of Diploglossus (Sauria: Anguidae) from Hispanola. Occasional papers of the Museum of Zoology, Baton Rouge: Louisiana State University 1971;40:1-9.

121. Verma PS. A manual of practical zoology: chordates. New Delhi: S. Chand \& Company Ltd.; 2007.

122. de Pous P, Mora E, Metallinou M, Escoriza D, Comas M, Donaire D, et al. Elusive but widespread? The potential distribution and genetic variation of Hyalosaurus koellikeri (Günther, 1873) in the Maghreb. Amphib Reptil. 2011; 32:385-97..

123. Blain HA, Bailon S, Agustí J. The geographical and chronological pattern of herpetofaunal Pleistocene extinctions on the Iberian peninsula. Comptes Rendus - Palevol. 2016:15:731-44.

124. Fluny A. Gerrhonotus liocephalus infernalis Baird in Texas. Herpetologica. 1949;5:65-7..

125. Tsellarius A, Tsellarius E. Behavior of Varanus griseus during encounters with conspecifics. Asiat Herpetol Res. 1997;7:108-30..

126. Traeholt C. Notes on the food and feeding behaviour of Varanus bengalensis nebulosus on Pulau Tioman, Malaysia. Malayan Nat J. 1997;50:173-81..

127. Randrianantoandro CJ, Andriantsimanarilafy RR, Randrianavelona V. A conservation framework for Furcifer chameleons in Madagascar; 2011.

128. Panov EN, Tsellarius AY, Nepomnyashchikh VA. Motor coordinations in behavior of the toad-headed agama (Phrynocephalus mystaceus; Reptilia, Agamidae): signal functions and endogenous rhythms. Entomol Rev. 2004; 84(Suppl. 2):S185-94..

129. Hairston NG. Observations on the behavior of Draco volans in the Philippines. Copeia. 1957;1957:262-5..

130. Howland JM, Vitt L, Lopez PT. Life on the edge: the ecology and life history of the tropidurine iguanid lizard Uranoscodon superciliosum. Can J Zool. 1990;68:1366-73.

131. Kavaliers M, Courtenay S, Hirst M. Opiates influence behavioral thermoregulation in the curly-tailed lizard, Leiocephalus carinatus. Physiol Behav. 1984;32:221-4.

132. Weese AO. Environmental reactions of Phrynosoma. Am Nat. 1919:53:33-54..

133. Townsend JH, Aldrich HC, Wilson LD, McCranie JR. First report of sporangia of a myxomycete (Physarum pusillum) on the body of a living animal, the lizard Corytophanes cristatus. Mycologia. 2005;97:346-8.

134. Pacala S, Rummel J, Roughgarden J. A technique for enclosing Anolis lizard populations under field conditions. J Herpetol. 1983;17:94-7..

135. Rieppel O, Kley NJ, Maisano JA. Morphology of the skull of the whitenosed blindsnake, Liotyphlops albirostris (Scolecophidia: Anomalepididae). J Morphol. 2009;270:536-57..

136. Allemand R, Boistel R, Daghfous G, Blanchet Z, Cornette R, Bardet N, et al. Comparative morphology of snake (Squamata) endocasts: evidence of phylogenetic and ecological signals. J Anat. 2017;231:849-68..

137. Angelici FM, Inyang MA, Effah C, Luiselli L. Analysis of activity patterns and habitat use of radiotracked African burrowing pythons, Calabaria reinhardtii. Isr J Zool. 2000;46:131-41.

138. Jayne BC. Comparative morphology of the semispinalis-spinalis muscle of snakes and correlations with locomotion and constriction. J Morphol. 1982;172:83-96..

139. Pough $\mathrm{FH}$. The morphology of undersand respiration in reptiles. Herpetologica. 1969;25:216-23.

140. Rieppel O, Maisano JA. The skull of the rare Malaysian snake Anomochilus leonardi Smith, based on high-resolution x-ray computed tomography. Zool J Linnean Soc. 2007;149:671-85..

141. Gower DJ, Captain A, Thakur SS. On the taxonomic status of Uropeltis bicatenata (Günther) (Reptilia: Serpentes: Uropeltidae). Hamadryad. 2008;33:64-82..

142. Sharma BK, Kandel RC. Assessment of python (Python bivittatus Kuhl) habitats in Bardiya national park. Nepal Ecoprint. 2015;22:85-90.

143. Yamasaki Y, Mori Y. Seasonal activity pattern of a nocturnal fossorial snake, Achalinus spinalis (Serpentes: Xenodermidae). Curr Herpetol. 2017; 36:28-36.

144. Ibrahim AA. The reptile community of the Zaranik protected area, North Sinai, Egypt with special reference to their ecology and conservation. Egypt J Nat Hist. 2004;3:81-92.

145. Gros-Désormeaux J-R, Lagabrielle E, Lesales T, Exilie I, Tupiassu L, Béchacq D. Living with or eradicating poisonous snakes in densely populated 
Caribbean islands - a socio-ecological challenge for the French West Indies. Open J Anim Sci. 2017;07:405-13.

146. Rasmussen JB. A review of the African members of the genus Micrelaps Boettger 1880 (Serpentes Atractaspididae). Trop Zool. 2002;15:71-87..

147. Shine R, Branch WR, Webb JK, Harlow PS, Shine T. Sexual dimorphism, reproductive biology, and dietary habits of psammophiine snakes (Colubridae) from southern Africa. Copeia. 2006;2006:650-64.

148. Bates MF. A re-evaluation of the taxonomic status of Xenocalamus bicolor concavorostralis Hoffman, 1940 (Serpentes: Atractaspidinae). South African J Zool. 1991;26:78-81.

149. Vences M, Glaw F, Mercurio V, Andreone F. Review of the Malagasy tree snakes of the genus Stenophis (Colubridae). Salamandra. 2004;40:161-79.

150. Petras D, Heiss P, Harrison RA, Süssmuth RD, Calvete JJ. Top-down venomics of the east African green mamba, Dendroaspis angusticeps, and the black mamba, Dendroaspis polylepis, highlight the complexity of their toxin arsenals. J Proteome. 2016;146:148-64..

151. Smith A, Meulders B, Michael Bull C, Driscoll D. Wildfire-induced mortality of Australian reptiles. Herpetol Notes. 2012;5:233-5..

152. Johnson CR. Defensive display behaviour in some Australian and Papuannew Guinean pygopodid lizards, boid, colubrid and elapid snakes. Zool J Linnean Soc. 1975;56:265-82.

153. Holm PA. Phylogenetic biology of the burrowing snake tribe Sonorini (Colubridae). Tucson: University of Arizona; 2008.

154. Bowler J. The colour of Seychelles wolf snakes Lycognathophis seychellensis on Aride. Phelsuma. 1999:7:64-6.

155. Edgren RA. The natural history of the hog-nosed snakes, genus Heterodon: a review. Herpetologica. 1955;11:105-17.

156. Whitfield Gibbons J, Luhring TM. Reptiles. In: Encyclopedia of inland waters; 2009. p. 497-505.

157. Doube M, Kłosowski MM, Arganda-carreras I, Fabrice P. BoneJ: free and extensible bone image analysis in ImageJ. Bone. 2010;47:1076-9..

158. Germain D, Laurin M. Microanatomy of the radius and lifestyle in amniotes (Vertebrata, Tetrapoda). Zool Scr. 2005;34:335-50.

159. Cleveland WS. Robust locally weighted regression and smoothing scatterplots. J Am Stat Assoc. 1979;74:829-36.

160. Shine R. Evolutionary advantages of limblessness: evidence from the pygopodid lizards. Copeia. 1986;1986:525-9..

161. Wiens JJ, Slingluff JL. How lizards turn into snakes: a phylogenetic analysis of body-form evolution in anguid lizards. Evolution. 2001;55:2303-18..

162. Feldman A, Sabath N, Pyron RA, Mayrose I, Meiri S. Body sizes and diversification rates of lizards, snakes, amphisbaenians and the tuatara. Glob Ecol Biogeogr. 2016;25:187-97.

163. Revell LJ. Phylogenetic signal and linear regression on species data. Methods Ecol Evol. 2010;1:319-29..

164. Pinheiro J, Bates D, DebRoy S, Sakar D. The nlme package. CRAN. 2007. www.cran.r-project.org. Accessed 15 Mar 2020.

165. Paradis E, Claude J, Strimmer K. APE: analyses of phylogenetics and evolution in R language. Bioinformatics. 2004;20:289-90.

166. Harmon L, Weir JT, Brock CD, Glor RE, Challenger W. GEIGER: investigating evolutionary radiations. Bioinformatics. 2008:24:129-31.

167. Amson E, Kilbourne BM. Trabecular bone architecture in the stylopod epiphyses of mustelids (Mammalia, Carnivora). R Soc Open Sci. 2019;6:190938..

168. Holm S. A simple sequentially rejective multiple test procedure. Scand I Stat. 1979;6: 65-70..

169. Smith SA, O'Meara BC. TreePL: divergence time estimation using penalized likelihood for large phylogenies. Bioinformatics. 2012;28:2689-90..

170. Huelsenbeck JP, Nielsen R, Bollback JP. Stochastic mapping of morphological characters. Syst Biol. 2003;52:131-58..

171. Schliep KP. Phangorn: phylogenetic analysis in R. Bioinformatics. 2011;27:5923.

172. Adams DC, Otárola-Castillo E. Geomorph: an R package for the collection and analysis of geometric morphometric shape data. Methods Ecol Evol. 2013;4:393-9.

173. Adams DC, Collyer ML. Phylogenetic ANOVA: group-clade aggregation, biological challenges, and a refined permutation procedure. Evolution. 2018;72:1204-15.

174. Freckleton RP, Harvey PH, Pagel M. Phylogenetic analysis and comparative data: a test and review of evidence. Am Nat. 2002;160:712-26..

175. Jolliffe IT. Principal component analysis. New York: Springer-Verlag; 2002.

176. David Polly P, Michelle Lawing A, Fabre AC, Goswami A. Phylogenetic principal components analysis and geometric morphometrics. Hystrix. 2013;24:33-41..

177. Wickham H. ggplot2. Wiley Interdiscip Rev Comput Stat. 2011;3:180-5.
178. Cao L, Moriishi T, Miyazaki T, limura T, Hamagaki M, Nakane A, et al. Comparative morphology of the osteocyte lacunocanalicular system in various vertebrates. J Bone Miner Metab. 2011;29:662-70.

179. Curtin AJ, Le P, Mouton FN, Chinsamy A. Bone growth patterns in two cordylid lizards, Cordylus cataphractus and Pseudocordylus capensis. African Zool. 2005:40:1-7.

180. Provete DB. Amphisbaena alba - ID: 0000000012070620 - CC BY-SA 2.5. CalPhotos University of California Berkeley. 2007. calphotos.berkeley.edu. Accessed 6 Mar 2020.

181. Flaxington W. Anniella alexanderae - ID: 0000000003142239 - CC BY-NC 3.0 CalPhotos University of California Berkeley. 2014. calphotos.berkeley.edu. Accessed 6 Mar 2020..

182. Freed P. Alopoglossus copii - CC BY 4.0. iNaturalist. 2012. mww.inaturalist.org. Accessed 6 Mar 2020.

183. Trainor C. Dibamus novaeguineae - CC BY 4.0. iNaturalist. 2018. www. inaturalist.org. Accessed 6 Mar 2020.

184. Harder H. Neuseeländische Brückenechse - public domain. In: Tiere der Urwelt von Wilhelm Bölsche. Hamburg Wandsbek: Verlag der Kakao Compagnie Theodor Reichardt GmbH; 1916. p. No. $28 .$.

185. Cebeci Z. Phoenicolacerta laevis - File: Lizard - Kertenkele 02.jpg - CC BY-SA 4.0. Wikimedia Commons. 2016. commons.wikimedia.org. Accessed 6 Mar 2020..

186. Basson H. Cordylus cataphractus - File: Ouroborus cataphractus03.jpg - CC BY-SA 3.0. Wikimedia Commons. 2015. commons.wikimedia.org. Accessed 6 Mar 2020.

187. Anderson J. Varanus griseus - public domain. In: Zoology of Egypt - volume first: Reptilia and Batrachia. London: Bernard Quaritch; 1898. p. PI. XVI..

188. Catenazzi A. Plestiodon reynoldsi - ID: 0000000011070774 - CC BY-SA 2.5. CalPhotos University of California Berkeley. 2007. calphotos.berkeley.edu. Accessed 6 Mar 2020.

189. Kwb. Plestiodon latiscutatus - File: Plestiodon_latiscutatus_110505.jpg - CC BY-SA 3.0. Wikimedia Commons. 2011. commons.wikimedia.org. Accessed 6 Mar 2020..

190. Fuhrmann T. Gekko gecko - File: Tokay_gecko_(Gekko_gecko)_-_Indonesia. jpg - CC BY-SA 4.0. Wikimedia Commons. 2019. commons.wikimedia.org. Accessed 6 Mar 2020.

191. Hartman T. Leiocephalus carinatus - Curly-Tailed Lizard on Cat Island - CC BY 2.0. Flickr. 2013. www.flickr.com. Accessed 6 Mar 2020.

192. Dupont B. Megatyphlops schlegelii - File: Schlegel's Beaked Snake (Rhinotyphlops schlegelii) (13800597024).jpg - CC BY-SA 2.0. Wikimedia Commons. 2015. commons.wikimedia.org. Accessed 6 Mar 2020.

193. Vassil. Python bivittatus - File: Python molurus bivittatus lle aux Serpents 201108 1.jpg - CCO 1.0. Wikimedia Commons. 2008. commons.wikimedia. org. Accessed 6 Mar 2020.

194. Reeder TW. Aprasia pulchella - CC BY-NC 4.0. iNaturalist. 2014. www. inaturalist.org. Accessed 6 Mar 2020.

\section{Publisher's Note}

Springer Nature remains neutral with regard to jurisdictional claims in published maps and institutional affiliations.

Ready to submit your research? Choose BMC and benefit from:

- fast, convenient online submission

- thorough peer review by experienced researchers in your field

- rapid publication on acceptance

- support for research data, including large and complex data types

- gold Open Access which fosters wider collaboration and increased citations

- maximum visibility for your research: over $100 \mathrm{M}$ website views per year

At $\mathrm{BMC}$, research is always in progress.

Learn more biomedcentral.com/submissions 